\title{
Probiotics: Versatile Bioactive Components in Promoting Human Health
}

\author{
Javad Sharifi-Rad $^{1}\left(\mathbb{D}\right.$, Célia F. Rodrigues ${ }^{2} \mathbb{D}$, Zorica Stojanović-Radić ${ }^{3}$, Marina Dimitrijević ${ }^{3} \mathbb{D}$, \\ Ana Aleksić ${ }^{3}$, Katarzyna Neffe-Skocińska ${ }^{4}$ (D), Dorota Zielińska ${ }^{4}$ (D), \\ Danuta Kołożyn-Krajewska ${ }^{4}$ (D), Bahare Salehi ${ }^{5,6, *(D)}$, Selvaraj Milton Prabu ${ }^{7}$, Francine Schutz ${ }^{8}$, \\ Anca Oana Docea ${ }^{9, *}$, Natália Martins $8,10,11, *$ (D) and Daniela Calina ${ }^{12, *(\mathbb{D})}$
}

1 Phytochemistry Research Center, Shahid Beheshti University of Medical Sciences, Tehran 1991953381, Iran; javad.sharifirad@gmail.com

2 LEPABE-Department of Chemical Engineering, Faculty of Engineering, University of Porto, 4200-465 Porto, Portugal; c.fortunae@gmail.com

3 Department of Biology and Ecology, Faculty of Science and Mathematics, University of Niš, 18000 Niš, Serbia; zstojanovicradic@yahoo.com (Z.S.-R.); dimitrijevicmarina92@yahoo.com (M.D.); 90anna.aleksic@gmail.com (A.A.)

4 Department of Food Gastronomy and Food Hygiene, Warsaw University of Life Sciences (WULS), 02-776 Warszawa, Poland; katarzyna.neffe.skocinska@gmail.com (K.N.-S.); dorota_zielinska@sggw.pl (D.Z.); danuta_kolozyn_krajewska@sggw.pl (D.K.-K.)

5 Noncommunicable Diseases Research Center, Bam University of Medical Sciences, Bam 44340847, Iran

6 Student Research Committee, School of Medicine, Bam University of Medical Sciences, Bam 44340847, Iran

7 Department of Zoology, Annamalai University, Annamalai Nagar 608002, Chidambaram, India; smprabu73@gmail.com

8 Department of Biomedicine, Faculty of Medicine, University of Porto, 4200-319 Porto, Portugal; francineschutz@yahoo.com.br

9 Department of Toxicology, University of Medicine and Pharmacy of Craiova, 200349 Craiova, Romania

10 Institute for Research and Innovation in Health (i3S), University of Porto, 4200-135 Porto, Portugal

11 Laboratory of Neuropsychophysiology, Faculty of Psychology and Education Sciences, University of Porto, 4200-135 Porto, Portugal

12 Department of Clinical Pharmacy, University of Medicine and Pharmacy of Craiova, 200349 Craiova, Romania

* Correspondence: bahar.salehi007@gmail.com (B.S.); daoana00@gmail.com (A.O.D.); ncmartins@med.up.pt (N.M.); calinadaniela@gmail.com (D.C.)

Received: 4 July 2020; Accepted: 25 August 2020; Published: 27 August 2020 updates

\begin{abstract}
The positive impact of probiotic strains on human health has become more evident than ever before. Often delivered through food, dietary products, supplements, and drugs, different legislations for safety and efficacy issues have been prepared. Furthermore, regulatory agencies have addressed various approaches toward these products, whether they authorize claims mentioning a disease's diagnosis, prevention, or treatment. Due to the diversity of bacteria and yeast strains, strict approaches have been designed to assess for side effects and post-market surveillance. One of the most essential delivery systems of probiotics is within food, due to the great beneficial health effects of this system compared to pharmaceutical products and also due to the increasing importance of food and nutrition. Modern lifestyle or various diseases lead to an imbalance of the intestinal flora. Nonetheless, as the amount of probiotic use needs accurate calculations, different factors should also be taken into consideration. One of the novelties of this review is the presentation of the beneficial effects of the administration of probiotics as a potential adjuvant therapy in COVID-19. Thus, this paper provides an integrative overview of different aspects of probiotics, from human health care applications to safety, quality, and control.
\end{abstract}


Keywords: nutrition; lifestyle; probiotic properties; evidence based-medicine; mechanisms; clinical studies; safety

\section{Introduction}

A frequent occurrence of lifestyle diseases and negative lifestyle habits in today's society has unquestionably triggered the development of food science and nutrition.

The current trend for healthy and rational eating is related to the increase in nutritional awareness among consumers, influencing the functional food sector at the same time. The sector includes natural and processed foods containing desirable biologically active molecules that, when administered in correct quantitative and qualitative proportions, provide clinically proven health benefits [1-6].

This kind of food has an unquestionable impact on the prevention, management, and treatment of chronic diseases in modern society provided that it is of a balanced nutritional value, proper composition, and endangers neither the health nor the life of a consumer [7].

Metabolomics studies have increasingly focused on the research directions in food and nutrition, specifically addressing food composition, physiology of healthy microbiota, and the nutrition and health relationship [8-11].

Probiotics can be defined as dietary supplements that contain live microbial strains capable of persisting in (or transiently colonizing) the human intestinal tract and confer a beneficial influence on host physiology, such as improving health. This process is particularly important when the normal, native flora has been disturbed: at this time, exogenously supplemented probiotics of a species/strain can temporarily colonize the intestinal tract and stabilize the microflora composition, thus restoring vital physiological function-a commensal flora [12].

The mechanisms of action of probiotics are diverse: they produce antimicrobial substances such as organic acids or bacteriocins, regulate the immune response through the secretion of $\operatorname{IgA}$ against possible pathogens, reduce the risk of developing an allergy, improve the function of the intestinal mucosal barrier, increase the stability or promote the recovery of the commensal microflora when it is disturbed, modulate the expression of host genes, release functional proteins such as lactase or natural enzymes, and decrease the adhesion of pathogens [13].

In addition to these probiotic properties, in the context of the current COVID-19 pandemic, new studies have shown that probiotics can be used in the prophylaxis and adjuvant therapy of this disease caused by SARS-CoV-2 [14,15].

Therefore, the use of probiotics to improve health is based on the following principle: exogenous microorganisms (from food sources) amplify the beneficial physiological effects of normal (indigenous) intestinal microflora.

According to the current state of knowledge, probiotic microorganisms show a number of beneficial properties to the human body, on multiple levels [16,17], and all are made safe by representing a Generally Recognized As Safe (GRAS) status, are acid- and bile-tolerant and able to adhere to the intestinal tract as well as colonise it. Moreover, probiotics are capable of protecting the host from noxious microorganisms and of strengthening the immune system [18]. However, both in the field of science and industry, the term "probiotics" is mainly narrowed to the group of lactic acid bacteria (LAB) [19].

Although microorganisms used in food production have a long history of safe use and are frequently familiar as "food grade" or GRAS microorganisms, the Joint Food and Agriculture Organization of the United Nations (UN) and World Health Organization (WHO) Expert Consultation on Evaluation of Health and Nutrition Properties of Probiotics started to establish several guidelines [20], for both monitoring and evaluating food probiotics. The first meeting was held in Canada (2002), and the team recognized and described the essential information to correctly validate health claims, besides establishing a set of mandatory assays to assess probiotics strains' safety [20]. 
Nonetheless, these regulations are not in law in any country, as noteworthy disparities are found among worldwide jurisdictions such as the European Community, Canada, and the United States. Since this meeting, a lot of clinical scientific data have triggered the development of probiotic-rich products in the market, and many misappropriations of the term "probiotic" have been reported. For that reason, in 2013, the International Scientific Association for Probiotics and Prebiotics (ISAPP) created the new concept of "probiotic" [21], as briefly pictured in Figure 1.

\begin{tabular}{|c|c|}
\hline 1 & $\begin{array}{l}\text { - Keep the FAO/WHO definition for probiotic: "live } \\
\text { microorganisms that, when administered in adequate } \\
\text { amounts, confer a health benefit on the host" }\end{array}$ \\
\hline 2 & $\begin{array}{l}\text { - Include the microorganism's species in the definition (has } \\
\text { been helpful to the host, in properly controlled studies) }\end{array}$ \\
\hline 3 & $\begin{array}{l}\text { - Specific claims (beyond "contains probiotics") must be } \\
\text { further substantiated }\end{array}$ \\
\hline 4 & $\begin{array}{l}\text { - Keep cultures, related with traditionally fermented foods, for } \\
\text { which is no evidence of a health benefit, out of this definition }\end{array}$ \\
\hline 5 & $\begin{array}{l}\text { - Keep undefined, faecal microbiota transplants out of this } \\
\text { definition }\end{array}$ \\
\hline 6 & $\begin{array}{l}\text { - New defined strains from human samples (commensals and } \\
\text { consortia), with suitable proof of safety and efficacy, should } \\
\text { be defined as "probiotics" }\end{array}$ \\
\hline
\end{tabular}

Figure 1. The new concept of "probiotic". Abbreviations: Food and Agriculture Organization of the United Nations (FAO), World Health Organization (WHO).

Unlike probiotics, which designate living microorganisms, bacteria mostly colonize the gastrointestinal (GI) tract; prebiotics are fibers that cannot be absorbed or broken down by the body and therefore serve as a food source for probiotics, especially the genus Bifidobacterium, increasing their number. They are indigestible food ingredients that beneficially affect the host by selectively stimulating the growth and/or activity of a limited number of bacteria in the colon, which can improve the health of the host [22].

Prebiotics are found naturally in foods such as artichokes, garlic, and onions, among others. It may be necessary to consume a large amount of these foods to have a "bifidogenic" effect-increasing the level of friendly bacteria in the intestine. For this reason, many people find it easier to take a prebiotic supplement or a combination of probiotics and prebiotic supplements (called symbiotics) to ensure that they reach the level of friendly bacteria [23].

Research shows that there are different types of prebiotics, in the same way that there are different types of probiotics. In prebiotics, the key differentiating factor is the length of the chemical chain, the short chain. The middle chain or the long-chain determines where in the GI tract the prebiotic has an effect and how the host can feel the benefits [22].

Common prebiotics includes inulin, fructooligosaccharides (FOS), galactooligosaccharides (GOS), lactulose, and lafinose. Prebiotics from FOS are low-molecular-weight carbohydrates and only promote the growth of probiotics [24]. Prebiotics from GOS are short-chain oligosaccharides, resistant to the digestive process in the upper GI tract, with the following roles: i) support the selective development of beneficial cells in the intestinal microbiota; ii) maintain the structure and functions of the digestive system; iii) maintain immune balance by the development of lymphoid tissue associated with the intestine (GALT) that stores immune cells; iv) support the balance of the intestinal flora, which can be influenced by various factors (e.g., diet, lifestyle, stress) [25]. The advantage of prebiotics is that they act synergistically with probiotics with symbiotic action and it is the most suitable option when an optimal repopulation of the flora is desired [24,25]. 
In this sense, and given the above-highlighted aspects, the present review article aims to provide a critical overview of probiotics use, drifting from its human health care applications to safety and quality control, viability, and safe consumption for clinical purposes.

\section{Methodology}

Scientific search engines PubMed, Scopus and ScienceDirect were searched to retrieve literature and cross-references using keywords: "probiotics", "prebiotics", "mechanism of action", "gastrointestinal disorders", "depression", "carcinogenesis", "immunostimulatory effect", "adjuvant therapy COVID-19", "food matrices", "probiotics viability", "side effects", " quality control”. Written papers in English, meta-analyses, and research articles and clinical trials were included. Short communications, abstracts, letters to the editors, studies that contained, and the administration of homoeopathic medicines were excluded.

\section{Effectiveness in Promoting Health: Mechanism of Action of Probiotics}

Probiotic preparations are also frequently used by healthy individuals, for preventive purposes, to obtain beneficial health effects and improve quality of life (Figure 2).

It has been observed that the microbiota has a variety of impacts on health and disease. The intestinal microflora is composed of microbes that are usually found in the intestine but can be affected by diet, lifestyle, exposure to toxins, and antibiotic therapy [2]. There is a relationship between health, disease, the immune system, and changes in the microbiota. It is believed that harmful bacteria begin to predominate in various disorders, such as obesity, autoimmune diseases, and infections. Probiotics play a role in maintaining the immune balance in the GI tract through direct interaction with immune cells. Thus, probiotics have become a tool to counteract "dysbiosis" by replacing the harmful microflora with beneficial microorganisms [26].

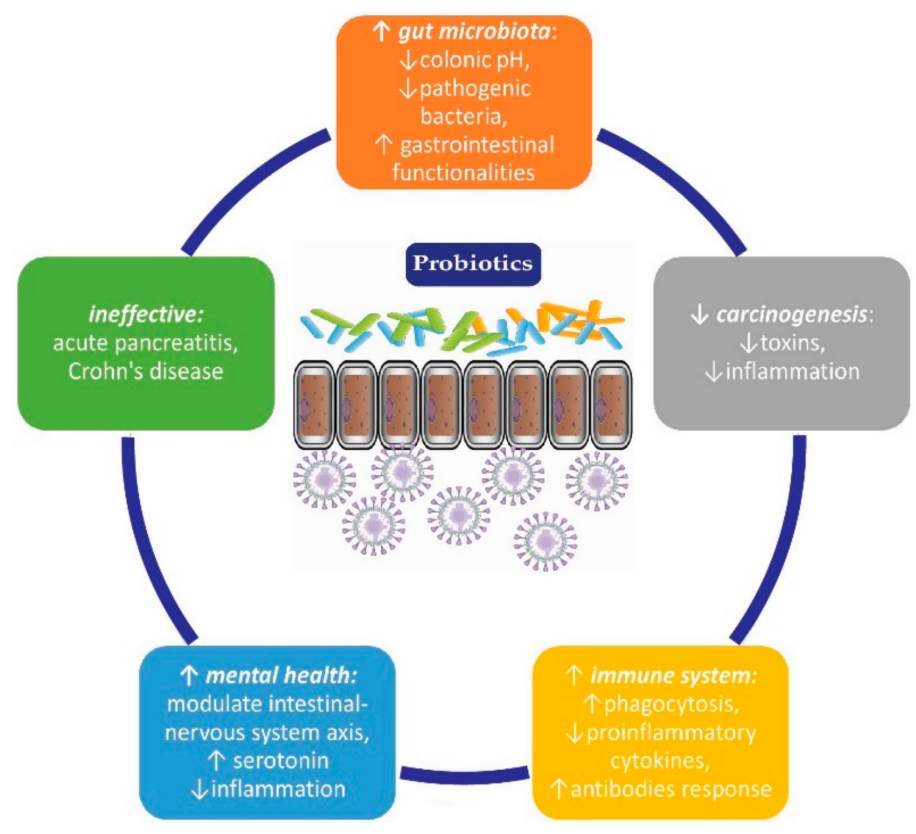

Figure 2. The most important beneficial properties of probiotics in promoting human health.

Most of the mechanisms behind the beneficial effects of probiotics are not yet known, but they are known to be multifactorial and to differ by species. Some of these mechanisms are related to the effects of probiotics to antagonize various harmful microorganisms through secretion of antimicrobial substances, competition for adhesion to the mucosa and epithelium, a strengthening of the intestinal epithelial barrier, and modulating the immune system. 


\subsection{Use of Probiotics in Gastro-Intestinal (GI) System Disorders}

The probiotic's effects on a human organism are extensive, and the clinical examination proves unquestionable beneficial effects of selected microorganisms in the treatment of GI system disorders.

\subsubsection{Acute Infectious Diarrhea}

At present, few therapeutic options change the course of the evolution of an acute infectious diarrheal disease, the treatment being generally a symptomatic one. Current guidelines encourage the association of probiotics in the treatment regimen. These have shown favorable results only in the case of enterocolitis of bacterial etiology; the results being inconsistent in viral infections. The administration of probiotics should be started at the onset of diarrheal disease and, although there is no evidence to support the duration of administration, it is recommended to continue for 1-2 weeks from the resolution of symptoms [27].

A meta-analysis of 63 clinical trials, including 8014 children and adults with acute infectious diarrhea, found a significant reduction in the duration of the disease with the use of probiotics (25 hours less), a 59\% decrease in the risk of prolongation over four days and a decrease in the number of daily stools. Another meta-analysis, which included 17 studies and 2012 children with acute diarrhea, showed a decrease of approximately $20 \mathrm{~h}$ in the duration of the disease in patients receiving probiotics [28].

The effectiveness of probiotics has also been proven in the case of traveler's diarrhea. Thus, in a meta-analysis of 12 clinical trials and 5171 patients, a 15\% reduction in the risk of developing traveler's diarrhea was observed in the case of prevention by probiotic administration starting two days before the trip and continuing during the trip [29].

However, a clinical study, which enrolled 646 children with acute diarrhea generally caused by rotavirus infection, did not show a significant difference between the group of patients who received the probiotic containing Lactobacillus rhamnosus GG and the control group in terms of concerns the frequency of stools, the duration of diarrheal disease, the presence of vomiting, or the duration of hospitalization [30].

\subsubsection{Diarrhea Associated with Antibiotic Therapy and Caused by Clostridium difficile}

One of the most significant health benefits brought by mentioned microorganisms is their bactericidal and bacteriostatic action towards pathogens. It is the lactic acid that performs the bactericidal function. It is able to neutralize the electrochemical potential of cell membranes, cause intercellular protein denaturation, and lower the $\mathrm{pH}$ level of pathogenetic cell cytoplasms. Other chemical compounds produced by probiotics that are able to inhibit pathogenetic bacteria growth and development are acetic acid, acetaldehyde, hydroperoxide, and specific peptides similar to antibiotics, called bacteriocins. The bacteria that are particularly sensitive to the activity of hydroperoxide are anaerobic of the Clostridium genus. Bacteriocins can inhibit Gram-positive pathogenetic bacteria growth, including Listeria sp., Staphylococcus sp., and Streptococcus sp. [31,32].

Regulating the proportions of gut microflora composition, probiotic microorganisms prevents or lessens the course of diarrhea. This property is of particular significance, especially in cases of diarrhea resulting from travelling effects and acute, chronic infectious diarrhea caused by viruses and bacteria of Clostridium difficile, Shigella, and Salmonella sp., and some Escherichia coli strains. The presence of probiotics in a digestive tract contributes to the reduction of a carrier state of pathogenic bacteria mentioned above as well as to the prevention of their adhesion to a gut lining. Supplying an organism with probiotic bacteria has a special function in the regeneration or formation of a gut microflora, which is crucial after antibiotic treatment or radiotherapy [33,34]. Experiments on mice infected by parasites show a similar preventative mechanism of probiotic effects, i.e., immune response stimulation and tight adherence to a gut lining. It was proven that probiotics are capable of preventing infections caused by parasitic Toxoplasma gondii and Cryptosporidium $[35,36]$. 
Probiotics are effective in the prevention and treatment of diarrhea associated with antibiotic therapy and in the prevention of diarrhea caused by C. difficile infection [37]. The administration of probiotics should be started on the first day of antibiotic therapy and continued for 1-2 weeks after the end of antibiotic therapy [38,39].

A meta-analysis of 23 studies looked at the effect of probiotics containing L. rhamnosus or Saccharomyces boulardii in preventing antibiotic-associated diarrhea in 3938 children. There was an 11\% decrease in the relative risk of developing diarrhea in those who received probiotics from the control group, including diarrhea associated with C. difficile infection, as well as reduced stool frequency, accelerated recovery, and reduced disease duration [40].

\subsubsection{Helicobacter pylori Infection}

The results are inconsistent in terms of the effectiveness of probiotics as an adjunct to antibiotic therapy to eradicate Helicobacter pylori infection. A meta-analysis of 8 clinical trials, which included 1163 patients, concluded an increase in the rate of eradication of $H$. pylori infection in combination with probiotics containing Lactobacillus. However, a meta-analysis of 21 clinical trials in 3542 patients did not reveal an improvement in the rate of eradication of the infection in combination with probiotics compared to placebo [41].

\subsubsection{Inflammatory Bowel Diseases (IBD)}

It is believed that it is possible to achieve beneficial effects by manipulating the microbiota in patients with inflammatory bowel disease [10,42]. Thus, the effectiveness of treatments aimed at dysbiosis present in inflammatory bowel diseases is being investigated. However, from the currently available data, it cannot be concluded whether the use of probiotics has a general benefit in the evolution of these diseases.

Probiotics are effective in increasing the remission rate in adults with ulcerative colitis, but not in maintaining remission. The administration should be started at the onset of exacerbation of colitis and continued for 1-2 weeks after the resolution of symptoms. A meta-analysis of 23 clinical trials involving 1763 patients, showed a $23.3 \%$ increase in the remission rate in patients with active ulcerative colitis when using probiotics [43].

Probiotics are a promising treatment option in irritable bowel syndrome, but the quality and quantity of existing evidence is quite low [44]. A meta-analysis of 23 clinical trials, which included 2575 patients with irritable bowel syndrome, showed a significant improvement in overall symptoms, bloating, and flatulence when using probiotics. Another meta-analysis of 21 studies (1639 patients) also showed an improvement in symptoms and quality of life compared to the control group [45].

\subsubsection{Chronic Constipation}

Probiotics are effective in children and adults with constipation. The administration should be started at the onset of symptoms and continued for as long as symptoms persist. In a meta-analysis of 2 clinical trials (165 patients with chronic idiopathic constipation), a significant increase in the average number of stools per week was observed in patients treated with probiotics, compared to the control group [46].

\subsubsection{Necrotizing Enterocolitis}

Probiotics reduce the risk of necrotizing enterocolitis and death in infants. Therapy should be initiated in children at risk of developing this disease and continued for as long as the risk remains high. A meta-analysis showed that the administration of probiotics significantly reduced the risk of severe necrotizing enterocolitis (effect observed in a group of 5529 patients) and mortality (effect observed in a group of 5112 children) [47]. 


\subsubsection{Hepatic Encephalopathy. Nonalcoholic Steatohepatitis}

Probiotics have shown favorable effects in hepatic encephalopathy [48]. A meta-analysis of 6 clinical trials, which included 496 adults with cirrhosis, showed a 15.3\% reduction in the relative risk of developing hepatic encephalopathy when given probiotics. In another meta-analysis of 21 studies involving 1420 patients, improvement in recovery and quality of life was observed with the use of probiotics, but without effect on mortality.

A systematic review of 3 clinical trials concluded that the administration of probiotics improves liver function in adults with non-alcoholic steatohepatitis based on biological markers, but lacks data on the effects on patients' clinical condition [49].

\subsubsection{Celiac Diseases, Non-celiac Gluten Sensitivity, Food Allergies}

Wheat has been a staple in the human diet for over 10,000 years [50]. The response to lifestyle and dietary protein in wheat can cause a variety of symptoms and immune responses. Gluten is a family of proteins found in cereals, often involved in several digestive pathologies, especially in early childhood. The spectrum of gluten-induced pathologies is increasing as new pathogenic mechanisms are understood and described. Three heterogeneous gluten-induced situations were identified: celiac disease (an autoimmune mechanism), wheat allergy (an allergic mechanism), and non-celiac gluten sensitivity (non-autoimmune, nonallergic). If the first two (celiac disease and a wheat allergy) have already become classics, being described, studied, and understood, the third entity-non-celiac gluten sensitivity-is a topic of attention as a new disease or syndrome with gluten intolerance [51].

Celiac disease is an autoimmune condition that manifests itself in inflammation of the small intestine caused by gluten consumption. Celiac disease (celiac disease) is the only autoimmune disease in which both the trigger, the epigenetic factor (gluten), but also the specific HLA antigen (human leukocyte antigen) are known. Unfortunately, celiac disease is underdiagnosed, and people with or without GI manifestations, symptomatic and asymptomatic subjects can be found [52]. Dysbiosis can promote celiac disease, and recent studies have established a link between dietary gluten (wheat, oats, barley, rye) and changes in the intestinal microbiome. Several studies suggest that modern lifestyle and eating habits may play a role in disrupting the balance of intestinal bacterial flora [53].

Thus, it has been shown that the intestinal microbiome is different in terms of composition in celiacs compared to healthy people. For example, the decrease in the number of Firmicutes bacteria and the increase in Proteobacteria have been found in both children and adults with celiac disease [54].

Other studies have reported a decrease in the population of protective, anti-inflammatory bacteria such as Bifidobacterium and an increase in Bacteroides and E. coli bacteria in patients with active celiac disease. Moreover, in these patients, low diversity and an altered metabolic function were discovered, which is associated with a decrease in the concentration of protective acids-short-chain fatty acids [55]. Studies have shown that mice colonized with healthy flora are protected from gluten-induced pathology, while mice colonized with Proteobacteria develop moderate gluten-induced pathology, and those colonized with E. coli from patients with celiac disease develop this disease [56].

Non-celiac gluten sensitivity is a new entity, introduced at the time of describing the gluten-induced pathology in individuals with symptoms similar to those of celiac disease, but without the presence of specific antibodies and intestinal lesions found in celiac disease. The mechanism of the disease is not elucidated. A possible role of wheat-induced innate immunity is suggested, as well as altered intestinal permeability, with excessive absorption of gluten-derived peptides. No predisposing genetic factor was identified. Recent data suggest the major role of the innate immune system through an abnormally born wheat-induced response. There is an increased expression of innate immunity markers (toll-like receptor TLR-2), increased $\mathrm{CD}^{+}$intraepithelial $\mathrm{T}$ cell density, and altered intestinal permeability ("leaky gut"), which lead to excessive absorption of gluten-derived peptides [57].

Food allergies can sometimes be fatal if the immune system overreacts. The foods involved in the most significant allergic reactions are peanuts, hazelnuts, walnuts, fish, seafood, milk, eggs, wheat, soy, and seeds [58]. The common mechanism that leads to various food allergies is a lack of immunological 
and clinical tolerance to ingested food, leading to immediate or acute reactions, mediated by specific antibodies, immunoglobulins E (IgE), or delayed clinical symptoms by a mechanism mediated by specific immune cells [59]. Sensitization (production of IgE antibodies) to food allergens can occur through the GI tract, skin, and, less frequently, through the respiratory tract. Currently, the "double exposure theory" suggests that allergenic food sensitization occurs through low-dose skin sensitization, especially when the skin barrier is affected, while the early introduction of food proteins induces oral tolerance [59].

Wheat allergy is an immune reaction to any of the hundreds of types of protein that are in wheat and that occur within minutes of the ingestion of food. A person allergic to wheat needs to avoid any product that contains wheat but tolerates other foods that contain gluten (rye, barley) [51].

The researchers found that the bacteria $C$. difficile, part of the intestinal flora, usually protects against peanut allergy, which is very common among the population and is currently incurable [60]. In a recent study, researchers genetically modified mice to make them allergic to peanuts. So, the first group of mice was raised in a sterile, germ-free environment, the second group of mice was treated with antibiotics shortly after birth, thus massively reducing their intestinal bacterial flora and another group of mice were raised normally. Mice in the first two groups had very strong immune reactions to peanuts, producing high levels of antibodies compared to mice whose intestinal flora was normal. This exaggerated sensitivity to peanut allergens could be greatly attenuated by reintroducing a mixture of Clostridium bacteria into the intestine of rodents [61].

On the other hand, the introduction of another type of intestinal bacteria, of the genus bacteroids, did not lead to any results, which shows that Clostridium bacteria play a unique role in protecting against allergies. Genetic and molecular analysis of Clostridium bacteria has shown how these microorganisms prevent allergic reactions, triggering a mechanism inside immune cells that produces large amounts of a molecule known to reduce intestinal wall permeability [62].

Peanut-allergic mice in the two study groups were treated either using the molecule, IL-22, or by introducing Clostridium bacteria into the gut [63]. In both cases, a clear decrease in the amount of allergens in the blood was observed. Researchers have shown that Clostridium bacteria are common to the human intestinal flora and are an obvious target for therapies for preventing or treating food allergies [63]. These results highlight the effectiveness of probiotic therapies, live microorganisms, bacteria or yeast, which, added to certain foods, such as yogurt or cereals, would have health benefits, by inducing an immune response that prevents allergens from entering the bloodstream, these bacteria minimize the body's exposure and prevent sensitization. This key mechanism leads to the development of allergies.

\subsubsection{Symptomatic Uncomplicated Diverticular Disease}

Uncomplicated symptomatic diverticular disease is a clinical condition characterized by chronic digestive symptoms such as recurrent abdominal pain, abdominal distension, and altered intestinal transit, secondary to the presence of diverticula. The clinical picture is similar to that present in irritable bowel syndrome, the semiological features that differentiate the uncomplicated symptomatic colonic diverticular disease being represented by pain located predominantly in the left iliac fossa, pain that persists over $24 \mathrm{~h}$; stools are frequently diarrhea, and symptoms do not resolve after defecation or flatulence [64].

The main objective in the management of the uncomplicated symptomatic diverticular disease is the control of abdominal symptoms. No therapeutic standard has been defined; however, optimal pharmacological and nutritional strategies for the management of uncomplicated symptomatic diverticular disease have been described.

Targeted therapeutic strategies have been developed on the intestinal microbiome: administration of dietary fiber, probiotics, or rifaximin. The therapeutic effect of fiber is not fully known. However, its administration by diet or in the form of supplements is encouraged to alleviate the symptoms of uncomplicated diverticular disease [65]. 
Their properties can explain the beneficial effect of fibers: they increase the mass of residue, stimulating intestinal transit, and act as prebiotics in the colon by promoting the proliferation of sanogenic species of intestinal flora: Bifidobacterium and Lactobacilli. The intestinal flora changes rapidly depending on changes in diet. However, there is no clear evidence of the therapeutic benefit of a high-fiber diet in the therapeutic control of the diverticular disease [66].

Following the idea of modulating the activity of the intestinal microbiota, the use of probiotics has recently been tried for the treatment of uncomplicated symptomatic $\mathrm{BD}$, but especially for the prevention of disease recurrences [65]. For the time being, however, the results are not very conclusive, the data being quite discordant. The most commonly used strains belonged to the genera Bifidobacterium and Lactobacillus, but strains of E. coli or other microorganisms, such as S. boulardii, were also used. What is certain is that certain probiotics for certain groups of patients with uncomplicated symptomatic bowel disease (BD) may bring some benefits. Still, in the absence of well-structured studies, it is difficult to say whether or not these benefits are comparable to those obtained from the use of therapeutic solutions (rifaximin-a, soluble fiber). As a result of the evidence, they have accumulated over time [66].

In Table 1 is summarized the data regarding the efficacy/ineffective effects of probiotics in GI diseases.

Table 1. Summarized data regarding the efficacy/ineffective effects of probiotics in GI diseases.

\begin{tabular}{|c|c|c|}
\hline Gastrointestinal Diseases/Disorders & Effect of Probiotics & Reference \\
\hline \multicolumn{3}{|c|}{ Efficacy of probiotics in gastrointestinal diseases } \\
\hline Acute Bacterial Infectious Diarrhea & $\begin{array}{c}\downarrow \text { duration of the disease, } \downarrow \text { the risk of prolongation over } \\
\quad \text { four days } \\
\qquad \text { the number of daily stools }\end{array}$ & [28] \\
\hline Traveler's diarrhea & preventive effect & [29] \\
\hline Acute viral diarrhea & $\begin{array}{c}\text { no significant difference between the group of patients } \\
\text { who received the probiotic containing Lactobacillus } \\
\text { rhamnosus GG and the control group }\end{array}$ & [30] \\
\hline Diarrhea associated with antibiotic therapy & $\begin{array}{c}\text { prevents or lessens the course of diarrhea } \\
\downarrow \text { stool frequency, } \uparrow \text { recovery, } \downarrow \text { disease duration }\end{array}$ & $\begin{array}{c}{[33,34]} \\
{[40]}\end{array}$ \\
\hline Helicobacter pylori Infection & $\begin{array}{l}\text { adjunct to antibiotic therapy to eradicate Helicobacter pylori } \\
\text { infection }\end{array}$ & [41] \\
\hline $\begin{array}{l}\text { Ulcerative Colitis, Irritable Bowel Syndrome, } \\
\text { Functional Abdominal Pain }\end{array}$ & $\begin{array}{l}\text { it cannot be concluded whether the use of probiotics has a } \\
\text { general benefit in the evolution of these diseases. } \\
\uparrow \text { remission rate in adults with ulcerative colitis, not } \\
\text { maintaining remission, } \downarrow \text { symptoms, } \uparrow \text { quality of life }\end{array}$ & $\begin{array}{l}{[43]} \\
{[45]}\end{array}$ \\
\hline Chronic Constipation & $\uparrow$ average number of stools per week & [46] \\
\hline Necrotizing Enterocolitis & $\downarrow$ the risk of severe necrotizing enterocolitis, $\downarrow$ mortality & [47] \\
\hline Hepatic encephalopathy & $\downarrow$ risk of developing hepatic encephalopathy & [48] \\
\hline Nonalcoholic Steatohepatitis & $\uparrow$ liver function & [49] \\
\hline $\begin{array}{c}\text { Celiac Diseases, Non-celiac Gluten Sensitivity, Food } \\
\text { Allergy }\end{array}$ & 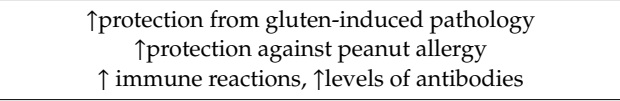 & $\begin{array}{l}{[56]} \\
{[60]} \\
{[61]}\end{array}$ \\
\hline Symptomatic uncomplicated diverticular disease & the therapeutic effect is not fully known & [66] \\
\hline \multicolumn{3}{|c|}{ Ineffectiveness of probiotics in gastro-intestinal disease } \\
\hline $\begin{array}{l}\text { Pancreatitis } \\
\text { Crohn's disease }\end{array}$ & $\begin{array}{c}\text { Ineffective } \\
\text { Insufficient evidence }\end{array}$ & [67] \\
\hline
\end{tabular}

\subsection{Mild and Moderate Depression}

Preclinical and clinical studies have suggested relief of depressive symptoms when using probiotics [68]. Favorable effects are thought to be mediated through the intestinal-nervous system axis and consist of reducing inflammation and increasing serotonin levels $[69,70]$.

According to a recent study, probiotics may be effective in reducing depressive symptoms in previously untreated patients with mild to moderate forms of depression. Patients were treated with probiotics containing two strains known to act on the intestinal-nervous system (Lactobacillus helveticus and Bifidobacterium longum). They showed a significant reduction in mood and sleep disorders after 
the use of probiotics for 4 weeks. The results were maintained at 8 weeks after treatment. The results, although preliminary, are important because probiotics have the advantage of not having the many side effects of antidepressant drugs [71].

\subsection{Potential Effect in Reducing Carcinogenesis}

Probiotic bacteria are capable of degrading and bonding carcinogenic compounds found in a diet or produced by pathogens. Among the compounds responsible for carcinogenesis we can classify enzymes such as nitroreductase, glucuronidase, and some mycotoxins. The experiments on animals demonstrate that probiotic bacteria can inhibit cancer cells growth, such as of abdominal hernia, sarcoma and leukemia. It is acknowledged that consuming a probiotic aliment may result in a decrease in the occurrence of colon cancer cases [72].

Probiotics play a significant role in neutralizing cancer, nonetheless, an accurate mechanism of anticancer action of probiotics has not been fully understood yet. In fact, this field of science requires in vivo models and clinical trials to assess the anti-cancer potential of probiotics. Presently, it is assumed that microorganisms having probiotic properties hinder the processes of the formation of noxious compounds of protein transition or fat oxidation through the inhibition of pathogen microorganisms' growth [73]. What requires particular attention is the products of protein transition, including carcinogenic, mutagenic or teratogenic biogenic amines and nitrosamines found in fermented meat products, such as raw aged meat.

Nutritional controversy of used nitrate III in meat technology is a subject of controversy as it is capable of forming toxic nitrosamines in situ and in vivo. Nitrosamines have carcinogenic properties to many species of animals. Moreover, they display mutagenic, teratogenic, and embryotoxic action [74].

$\mathrm{N}$-nitrous compounds may arise in food products during technological processes, food storage, and directly inside a human body as a result of the activity of digestive tract microorganisms, which are responsible for reducing nitrate $\mathrm{V}$ to nitrate III, oxidizing ammonia to nitrites, and degrading proteins to the II-row amines. These N-nitrous compounds, which can occur in food during technological processes are an important risk factor for gastric cancers [75]. The majority of nitroso-compounds are formed in the process of endogenous synthesis. The bacterial reduction is started in the mouth and is continued in the stomach through its low $\mathrm{pH}$ level. Nitroso-compounds formed in a stomach, are able to diffuse over long distances through permeation to other organs. The large intestine is also an environment of unfavorable chemical reactions undergone by amino acids, amides, indoles, phenols, and glycocholic acid. Probiotic starter cultures added to food should inhibit or reduce negative reaction from the perspective of proteolytic transition, which influences the security of finished products [76].

\subsection{Immunostimulatory Effect}

Regarding the role that the immune system plays in maintaining and improving health, from a traditional point of view, immunity is seen as a defense system against intrinsic factors (neoplasms and tumors) and extrinsic factors, causative agents of diseases (pathogens). On the other hand, this definition presents only a part of the whole.

By controlling and orchestrating the immune response, the immune system is also able to regulate inflammatory events and control and limit the progression of certain pathologies. This occurs mainly through the production of modulating hormones (cytokines) that are able to shape and modify the character of an immune or inflammatory reaction. In this context, it should be obvious that the microbes present in the intestine are not just passive residents of the mucosa of the GI tract. Most likely, the signals generated by the interactions between the microorganisms of the GI tract and the immune system are responsible for most of the beneficial effects of probiotics on health [77].

Probiotic bacteria are capable of stimulating specific and nonspecific defense mechanisms in a human body. The use of probiotics is recommended when the immunity of an organism weakens, which lowers the risk of the occurrence of inflammation, allergies, or infection [78,79]. 
Probiotic preparations have proven their beneficial influence in the clinical course of eczema among children allergic to the proteins present in cow milk. The research has also indicated that traditional treatment with the use of an elimination diet resulted in health improvement among over a half of tested children, while using probiotics increased the percentage of children exhibiting health improvement to $90 \%[36,80]$. Breast-fed babies provide another example of the stimulating effect of probiotics on the immune system. Bifidobacterium sp. detected in the feces of children resulted from the increased level of IgA antibodies, which did not relate to the babies fed with formula milk [81]. A suitable probiotic supplementation is also recommended to pregnant women and babies under 12 months old [82].

Song et al. [83] demonstrated the anti-allergic potential of L. plantarum L67 and its application to yogurt. Immunomodulation within a human body is one of the most completely elucidated aspects of the health-enhancing effects of probiotics.

Additional studies on L. rhamnosus GG have shown that probiotics can attenuate immune-mediated atopic manifestations by supplementing infant or maternal nutrition, may partially control the immune-mediated inflammatory response in adults (by regulating the expression of leukocyte inflammation receptors), and may reduce the incidence and severity of diarrhea in infants while increasing the number of circulating antibodies [84].

Probiotics are able to modulate the immune system via immunostimulation and immunoregulation, and thus have a significant impact on health and disease status, which have an intrinsic immune component. In the case of immunostimulation, probiotics can provide an amplification of the immune response in key aspects of effector mechanisms specific for combating infectious diseases or intrinsic pathologies, such as the development of neoplasms. In addition, the ability of probiotics to stimulate cytokine secretion can provide a very important regulatory function in controlling conditions characterized by immune dysfunction, such as chronic inflammation and allergies [85].

Administration of fermented dairy products containing Lactobacillus johnsonii La1 or Bifidobacterium lactis $\mathrm{Bb} 12$, for 3 weeks resulted in an improvement in the phagocytosis capacity of leukocytes in the peripheral blood. The increase in phagocytosis was sustained for several weeks after discontinuation of probiotics, with granulocytes exhibiting higher phagocytic activity than monocytes. Increases in the expression of various receptors involved in phagocytosis have also been observed in neutrophils, phagocytic index, or bactericidal capacity [86].

Aging is associated with immunodeficiency, suggesting that probiotics may correct the decline in phagocytic cell function associated with aging. L. rhamnosus and B. lactis resulted in a significant increase in phagocytic activity of neutrophils and monocytes, especially in subjects with impaired immune function prior to surgery.

It was observed that phagocytic activity is correlated with age, subjects over 70 years of age having a greater improvement in phagocytic activity than those under 70 years of age following probiotic supplementation. Several studies have reported an improvement in the activity of NK (natural killer) immune cells and the percentage of NK cells in the peripheral blood in subjects who received probiotics, as in the case of phagocytic activity.

Numerous studies have demonstrated the ability of certain strains of probiotics to potentiate the humoral immune response to infections. In children with rotavirus-induced diarrhea, administration of Lactobacillus GG resulted in a significant increase in IgG, IgA, and IgM levels [86].

Stimulation of post-vaccination immunogenicity was also observed. Administration of B. bifidum and L. acidophillus La1 resulted in a 4-fold increase in the IgA autoimmune response following immunization for Salmonella typhi, while Lactobacillus GG improved the response to the oral rotavirus vaccine. Certain strains of probiotics have improved the immune response to immunization with the polio virus: L. rhamnosus and L. paracasei have stimulated the autoimmune response, especially IgA and the secretion of specific anti-polio IgG and IgA immunoglobulins. These observations suggest the potential adjuvant effects of probiotics in improving vaccine efficacy [87]. 
The protective effect of the Shirota strain of $L$. casei in the recurrence of colon cancer after surgery has been demonstrated. The increase in the percentage of helper $\mathrm{T}$ and NK lymphocytes in adults with colorectal cancer suggests that the effect of $L$. casei on immune function plays an important role in suppressing tumor cell development. The host immune response can be stimulated by B. longum subsp infantis 35624 (B. infantis), causing tumor suppression or regression [88].

The mechanisms by which probiotics influence the immune response are not fully understood and known. It is estimated that certain probiotic molecules are recognized by specific receptors in immunocompetent cells (monocytes, macrophages, dendritic cells, etc.), causing the release of inflammatory cytokines. Numerous studies have also reported increased IL-1, IL-2, IL-6, IL-10, IL-12, IL-18, TNF- $\alpha$, and $\gamma$-interferon production due to in vitro leukocyte stimulation as a result of prebiotic supplementation. Other evoked effects of probiotics on the immune system are regulation of the ratio of T-helper1 / T-helper 2 cells; and a stimulation of the proliferation of intraepithelial lymphocytes [89].

\subsection{The Potential of Probiotics in Prophylaxis and Adjuvant Therapy in COVID-19}

In January 2020, the World Health Organization (WHO) stated that there is an emergency situation related to the outbreak of an infection caused by a new type of virus in the coronavirus family [90]. The new type of coronavirus was named SARS-CoV-2, and the disease was downgraded by infection with this virus to COVID-19. With the exception of Remdesivir, there is currently no approved treatment or vaccine for COVID-19 [91]. In COVID-19 disease management, a therapeutic strategy involves antiviral, anti-shock, anti-hypoxemia, anti-infective, maintenance of the electrolyte and microbiota balance. Multidisciplinary and individualized treatment was applied to each to increase the therapeutic effect [92]. Thus, researchers around the world have conducted various studies in search of possible adjuvant treatments such as natural bioactive compounds, vitamins, and trace elements.

A recent study showed that SARS-CoV-2 behaves like a bacteriophage, meaning a virus that infects bacteria [93]. Genetic sequencing of microflora from six severely infected COVID-19 patients in the same family showed the presence of significant amounts of Prevotella in the feces [94]. This could explain the large variations in viral load from one test to another in the same person. The hypothesis is that the virus infects these bacteria, which then cause inflammation, sometimes fatal. Infections involving Prevotella are already known to cause acute respiratory symptoms. If COVID-19 is proven to be a mixed infection, both viral and bacterial, then the benefit of combining hydroxychloroquine and azithromycin is scientifically supported. In particular, azithromycin attacks Prevotella and intracellular microbes [95]. Several patients experienced a marked decrease in bifidobacteria and lactobacilli in the intestine. They were given probiotics and prebiotics to restore balance and prevent risk of secondary infections [96]. Antibiotic therapy has been reserved for people with a long history of disease and repeated fever. The L. plantarum strain, acting on the intestinal mucus, made it possible to prevent epithelial cell infection by coronaviruses in an animal model study [97].

In chronic inflammatory diseases, ingestion of a high concentration probiotic complex also allows a reduction in the plasma level of proinflammatory cytokines and an increase in the level of cytokines that regulate inflammation, with changes in the fecal microbiota compared to the control group [77]. Another probiotic complex, using Lactobacillus brevis as the dominant strain, showed similar results, but acting on the intestinal-brain axis by immune, metabolic, and nervous pathways [98]. It is noteworthy that Lactobacillus brevis, a species of lactic acid bacteria, is able to prevent Prevotella from forming biofilms. These biofilms are one of the means used by bacteria to protect themselves from the immune system and antibiotics [99]. Finally, obese people, who are more affected by Covid-19, have a microflora that is even richer in Prevotella [100].

If the administration of probiotics to this population gives results in terms of improving the markers of obesity (fat mass, blood sugar, insulin, etc.), these results are even more visible to individuals in whom the bacteria were present. 


\subsection{Diseases in Which Probiotics are Ineffective}

Probiotics are ineffective in acute pancreatitis and Crohn's disease. A meta-analysis of 6 clinical trials evaluating 536 patients with severe acute pancreatitis showed that the use of probiotics did not lead to significant changes in the rate of infection, the total number of infections, the rate of operations, the duration hospitalization, or mortality. Insufficient evidence was also recorded in the case of 3 analyses on the efficacy of probiotics in patients with Crohn's disease in order to induce remission, maintain remission, or prevent the postoperative recurrence rate [67].

\section{Probiotics as Pharmaceutical Dietary Supplements}

Among the probiotic microorganisms that exhibit a prevailing occurrence in food, pharmaceutical industries encountered Lactic acid bacteria (LAB) belonging to the Lactobacillus and Bifidobacterium genera. Probiotic LAB used in food fermentation are safe for consumption with food as well as in the form of dietary supplements. However, it is noteworthy that the effectiveness and health benefits depend not exclusively on the strain of probiotic microorganisms, but also on the geographical origin of a strain and on the place of a living population taking the probiotic [101].

The related literature reveals the marked influence of isolation environment on suitable microorganisms' selection for probiotic preparations: dietary supplements, as well as starter cultures for food production. In the conducted scientific research, it was proven that the gut microbiota can be characterized by a unique constitution depending on the origins of an organism, both human and animal, taking into account such aspects as various geographical areas, climate zones, or eating habits $[102,103]$.

Furthermore, literature data indicate that multi-strain dietary supplements are at an advantage over single microorganisms, because combining several strains may expand the range of preparation properties, such as by broadening the spectrum of antimicrobial action [104,105]. What is worth noticing is the fact that probiotics provided in a form of dietary supplements or within food are not medicinal products. Their influence on an organism and health benefits depend on several factors, including the source of a strain, with spontaneously fermented food being particularly beneficial to the human digestive tract, as well as geographical origins of a strain, supplemented population match, and production process, like food additives, humidity, $\mathrm{pH}$, fermentation, and storage or freeze-drying conditions [36,106].

Simone et al. [107] suggested in a recent study that the probiotic products contain not only live bacteria but also dead cells, their fragments and even molecules. During the process of fermented food or pharmaceutical supplements production, dead bacteria and their fragments cannot be separated and removed from live probiotic cells. Thus, further studies are needed to show whether the presence of dead bacterial cells is positive, negative, or neutral to the health and nutritional value of such products $[105,108]$.

Scientific studies conducted worldwide reveal that probiotic bacteria supplied with food adapt easier to the GI tract environment and have better health potentialities than those consumed through a form of pharmaceutical preparations $[7,109,110]$. In the EU countries, consumers can easily access multiple probiotic preparations. However, only few of them show scientifically confirmed beneficial health effects. Moreover, the majority of such products' labels contain neither the proper nomenclature of probiotic species nor a strain for the recommended dose conferring therapeutic effects $[36,107]$.

Fermentation in the small intestine lowers the $\mathrm{pH}$ level, which increases the absorption of calcium and other mineral constituents. The results of scientific research suggest that probiotic bacteria exhibit therapeutic effects on hepatic encephalopathy as well as antagonizing H. pylori growth, the major cause of gastric and duodenal ulcers. Probiotic supplementation may favorably affect the treatment of peptic ulcer disease, particularly due to the use of antibiotics [16,17]. In summary, in addition to the listed probiotic properties, in the recent literature can be found information about anti-diabetic, anti-obesity, anti-inflammatory and angiogenic activity of probiotics microorganisms [16,111,112]. Additionally, 
an important phenomenon is the effect of probiotics on the human brain, namely on the synthesis of neurotransmitters that helps to suppress anxiety and depression [16,113].

In recent years, knowledge on the human microbiome, especially connecting human resident microbes and physiology, has become very important. The field of the nutritional value of food is influenced in part by a person's gut microbial community (microbiota) and its component genes (microbiome). Probiotic foodstuffs have been shown to cause alteration in the human gut microbial content and to have a positive impact human health $[80,114,115]$. Undoubtedly, what is really important for the proper functioning of an organism is the intestinal microbiota composition as well as its replenishment mainly through the consumption of food products containing selected bacteria strains.

\section{Particular Food Matrices and their Protection Role on Probiotic Viability}

It is acknowledged that probiotic strain administration needs to be prudently calculated. First, it is essential to analyze if fermented or not-fermented food could be more appropriate to stimulate the required effect. Then, to determine whatever food matrix, i.e., raw material to which probiotics can be placed to be accepted as a food product, will be more suitable. Actually, the description of: (i) specific probiotic strains, (ii) food matrix, and (iii) dietary content interaction with probiotics are the latest research topics for food technology and industrial experts [116].

Hence, to evaluate the food matrix, it is crucial to assess the technological skills needed to get a sensorial accepted product and to take into consideration the protective function of probiotics through their passage in the digestive tract. In both cases, the most critical is to preserve alive the highest number of probiotic bacteria, which will rely on a matrix's chemical composition and its physical state. The food substrate composition (e.g., carbohydrates, fat, proteins) and $\mathrm{pH}$ can disturb the growth, stability, and survival [7] of probiotic microorganisms during GI transit. Numerous matrices are vehicles for delivering probiotic bacteria in GI and are considered the basis for probiotic food development [117].

Introduced probiotic bacteria can origin fermentations or be in the not-fermented product. Traditionally, the probiotics used in dairy beverages is broadly extended and milk is the most popular food matrix. Despite milk containing the required growth factors for probiotic growth, it does not necessarily mean that they are available in the assimilable forms, nor in optimal doses. On the other hand, several studies have reported that vegetable and fruit juices or pulp addition (prebiotic) may have deleterious effects on probiotic strain viability, due to its acidity and mostly by the presence of antimicrobial compounds (i.e., phenolic compounds) [110]. For instance, many factors may affect Lactobacillus sp. and Bifidobacterium sp. viability in dairy beverages, such as the probiotic strains used, $\mathrm{pH}$, the presence of hydrogen peroxide and dissolved oxygen, the metabolite concentration (lactic and acetic acids), the medium buffering capacity, storage temperature, and the nature of added ingredients $[7,110]$. The main strategies to overcome this problem involves the dairy beverage's supplementation with whey protein concentrate, that has a higher buffering capacity compared to caseins subsequently delaying the post-acidification during storage. In addition, sulfur amino acid release in heat treatment of whey may lessen the redox potential, producing a positive effect on probiotic survival [110].

Other dairy foods are considered good vehicles for Lactobacillus and Bifidobacterium species, such as hard or semi-hard cheese. The only problem can be salt concentration, so the viability and activity must be guaranteed at the time of consumption. In several studies, L. acidophilus, L. plantarum, and L. pentosus have been largely introduced into pasteurized hard and semi-hard cheeses as the sole starter. These reports have shown that probiotic survival during the storage period declined when storage time and/or salt concentration are augmented [118].

In some cases, fermented milk products are fermented by monocultures of probiotic bacteria, but routinely supporting cultures are applied to speed up the acidification process and to deliver the desired texture and flavor. Several Lactobacillus sp. and Bifidobacterium sp. survive in fermented 
milk products for 4-8 weeks under refrigeration. Casein glycomacropeptide, amino sugars, and oligosaccharides support these probiotics' growth, leading to the development of probiotic foods [119].

In the research of Neffe and Kołożyn-Krajewska [120] and Neffe-Skocińska et al. [121], it was found that L. casei ŁOCK 0900 and ŁOCK 0908 strains, added to cured pork loins, reached a total of $10^{7} \log \mathrm{CFU} / \mathrm{g}$, while in samples with $0.2 \%$ glucose, the total count was $10^{8} \mathrm{log} \mathrm{CFU} / \mathrm{g}$. In addition, and considering the storage conditions, the authors found higher LAB bacteria growth, including $L$. casei ŁOCK 0900, in pork loins during the 21-day ripening period at $20^{\circ} \mathrm{C}$ (from $10^{7}$ to $10^{8} \mathrm{CFU} / \mathrm{g}$ ) and the lowest in loin samples aged at $16^{\circ} \mathrm{C}$ (from $10^{4}$ to $10^{6} \mathrm{CFU} / \mathrm{g}$ ). Moreover, Wójciak et al. [122] revealed that $L$. casei ŁOCK 0900 and L. paracasei ŁOCK 0919 may be effectively used as ingredients in fermented sausage production.

Meat products-containing probiotic production is still in development and is much more problematic than producing other probiotic products, as they have the characteristics of a raw material. In fact, meat products create a suitable environment for microbiota growth, so lately multiple efforts have been made to use probiotics in these products. Conversely, meat probiotic products manufacture demands surpassing some technological limits, such as the meat native microflora, the need to employ certain additives (e.g., nitrites, salt), lower the water activity, and lower the amount of natural sugars.

The dry meat matrix consists of meat and fat which "encapsulate" bacteria, protecting them from the critical passage of the GI tract. Moreover, they are typically not or are only slightly heated, being thus suitable for probiotic carriage into the human GI tract. All this promotes a buffer effect in bacteria $[123,124]$.

The quality traits of these kind of products is narrowly connected to the maturing during drying; the long-term storage and growth of probiotic microorganisms evidently has a great impact on its sensorial, nutritional, safety, and other features. In fact, the key matter is that these strains should be present at similar levels to have the desired health potential on consumers' gut flora. Klingberg et al. [125] showed how important the LAB use was, also indicating the high preservation of CFU of viable cells, both at the time of consumption and during the storage time. Some authors signposted that probiotic bacteria could be better adjusted at the meat environment than at LAB ones [124].

Likewise, changes in $\mathrm{pH}$ also pose a survival challenge for fermented meat products containing probiotics. A reduction in $\mathrm{pH}$ from 5.6 to 4.9 post-fermentation limits probiotic survival (L. rhamnosus GG and E-97800) in fermented sausage over fermentation and ripening processes [126]. Thus, fermented sausages can be manufactured using L. acidophilus and B. animalis strains, although in the case of Bifidobacterium spp. their use as a starter culture has led to several complications such as its low content post-fermentation and its absence after long storage periods (60 days). The opposite scenario is found with the L. acidophilus strain when used as a starter culture: high counts $\left(10^{6} \mathrm{CFU} / \mathrm{g}\right)$ and viable for more than 60-day storage [127]. On the other side, probiotic bacteria sensitivity to curing agents (i.e., sodium chloride and sodium nitrite) is also challenging in meat fermentation, although several strategies have been applied to overcome this issue. For example, the use of UV irradiation triggered the generation of L. gasseri mutants able to resist these compounds [128], but microencapsulation has also shown to be promising [129].

Considering that probiotics are applied as additives in food, so as to deliver several health benefits, several studies have also been conducted to determine the in vitro adhesion of several LAB probiotic strains to intestinal cells, it being found that L. plantarum strains have larger adhesion rates to intestine intimae than those isolated from a sausage (L. brevis and L. paracasei) [130]. In cereals and legume fermentation, probiotics have also been increasingly used, given its richness in sugars, that can be used as carbon sources by probiotic strains. Specifically, the ability of cereal-based products to maintain probiotic growth is related to their concentration in fibers (e.g., xylooligosaccharides, xylan, arabinoxylan), a growth substrate for probiotics. Moreover, cereals also have a high content in minerals, vitamins, sterols, and other growth factors, supporting the probiotics' growth, including LAB [117]. More recently, soy products have been assessed as potential probiotic vehicles. In fact, soy 
has been evidenced to be an outstanding raw material on non-dairy probiotic food development [116]. In addition, peanuts have also been recently studied for probiotic food formulation [131].

An interesting novel approach would be to incorporate probiotics in a dry food matrix. Yet this involves more distinct challenges than liquid probiotic products. A 2004 report described the detection of $B$. lactis in the feces of healthy human volunteers after consumption of an oat-based cereal bar containing B. lactis Bb-12 [132]. As main conclusions, the authors stated that dry food matrices keep the probiotic quality equal as dairy products and may then extend probiotic use and shelf-life.

Still considering fruits and vegetables as key nutrient sources (i.e., minerals, vitamins, dietary fibers, and antioxidants), they have been stated as perfect substrates for probiotics growth, with good acceptability rates between all age groups [110]. In this sense, fermented vegetable and fruit juices containing probiotics have been increasingly designed for therapeutic purposes. Since consumers' demands for non-dairy-based probiotic products have largely been augmented, vegetable or fruit juice-based probiotic drinks have reached a relevant status. Actually, many native LABs have been identified in raw vegetables, such as L. plantarum, L. paracasei, L. casei, L. delbrueckii, and L. brevis, isolated from natural vegetable lactic acid fermentation. However, the use of probiotic cultures in these foods are, indeed, a great challenge given the above-listed constrains. At large, probiotics growth and viability in fruits and vegetable drinks hang on elements such as bacterial species and strains used, $\mathrm{pH}$, and lactic and acetic acid concentration in the final product [110].

However, as has already been explained, it has been reported that these foods are, in fact, good matrices for probiotic growth. Peeling and cutting vegetables raises the minerals, sugars, vitamins and other nutrients released from the cellular content, which creates a good environment for microbial growth [133]. For instance, carrot juice seems to be a good growth medium for both $L$. rhamnosus and $L$. bulgaricus growth, with a significant load post-fermentation $\left(10^{9} \mathrm{CFU} / \mathrm{mL}\right)[110]$.

Carrot juice is reported to naturally have $\approx 2 \%(\mathrm{w} / \mathrm{v})$ of sucrose, $1 \%(\mathrm{w} / \mathrm{v})$ of glucose and $0.8 \%(\mathrm{w} / \mathrm{v})$ of fructose, the main carbon and energy sources for probiotic growth. Additionally, carotenoid content ( $\alpha$-and $\beta$-carotene) is partially affected by probiotic bacteria metabolism over fermentation $[110,134,135]$. Moreover, cabbage has been shown to be a good medium for probiotics' growth [136], it being even proposed by Jaiswal and Abu-Ghannam that probiotic cabbage juice consumption can be a functional beverage for vegetarians and/or dairy food-allergic consumers [137]. Indeed, fresh cabbage juice revealed a high viable cell count of L. brevis, L. plantarum, and L. rhamnosus (9-10 log CFU/mL), during weeks of storage. In another report from the same authors, L. plantarum C3, L. casei A4, and L. delbrueckii D7 demonstrated to also be able to rapidly grow in sterilized cabbage juice without any nutrient supplementation [137].

Nonetheless, given the higher acidic $\mathrm{pH}$ in these products and consequently the high vulnerability of some probiotic strains, microencapsulation appeared as a key strategy to offer protection to acid-sensitive probiotics, since encapsulated probiotics survived over 6 weeks of cold storage with more than $10^{5} \mathrm{CFU} / \mathrm{mL}$ or $\mathrm{g}$, as free probiotic cells lost their viability within 5 weeks. Besides, complementing these foods with prebiotics is also a good strategy to improve probiotics' viability and stability [117]. Thus, microencapsulation in sealed capsules of different materials have been the most widely used, releasing their content under specific environments. Among these materials, lipids such as oil emulsions, milk fat, and water insoluble microcapsules appear to be of high interest. Furthermore, a combination of two different approaches have appeared as a feasible solution [138].

Additionally, the use of a food matrix naturally containing a high content of ingredients with protective effects can also be implemented. As the lipid fraction of cocoa butter has shown to protect bifidobacteria, the feasibility of using chocolate as a carrier for a microencapsulated mixture of probiotic L. helveticus CNCM 1-1722 and B. longum CNCM 1-3470 has also been assessed, and the results indicated the association of a chocolate coating with microencapsulated probiotic strains as an excellent solution [138]. In fact, it is known from the medical point of view that low-moisture foods can act as efficient carriers for small amounts of pathogens, thus leading to human infections, as was also shown by a recent chocolate-related outbreak of salmonellosis in the UK [138]. 


\section{Probiotics: Safety and Quality Control}

Safety and efficacy regulation are key factors in the context of "consumer protection law", and probiotics comprise an excellent example of worldwide attention. There is no news of the raising demand for probiotics due to their well-documented bioactive effects. Delivered through foods, drugs or dietary supplements, infant formula, natural products, among others, different safety requirements exist for each product category [139].

Currently, it is recognized that a probiotic is accepted as a drug when it cannot be added to food; nonetheless, food probiotics and dietary supplements entail less proof to achieve an authority's approval in comparison with a long and costly process of drug search/discovery besides constraining the manufacturer's relevance in clinical studies [140]. Probiotics are of extreme heterogeneity, i.e., two probiotic strains may exactly exert similar clinical effects, but may present distinct safety profiles (Figure 3) [141].

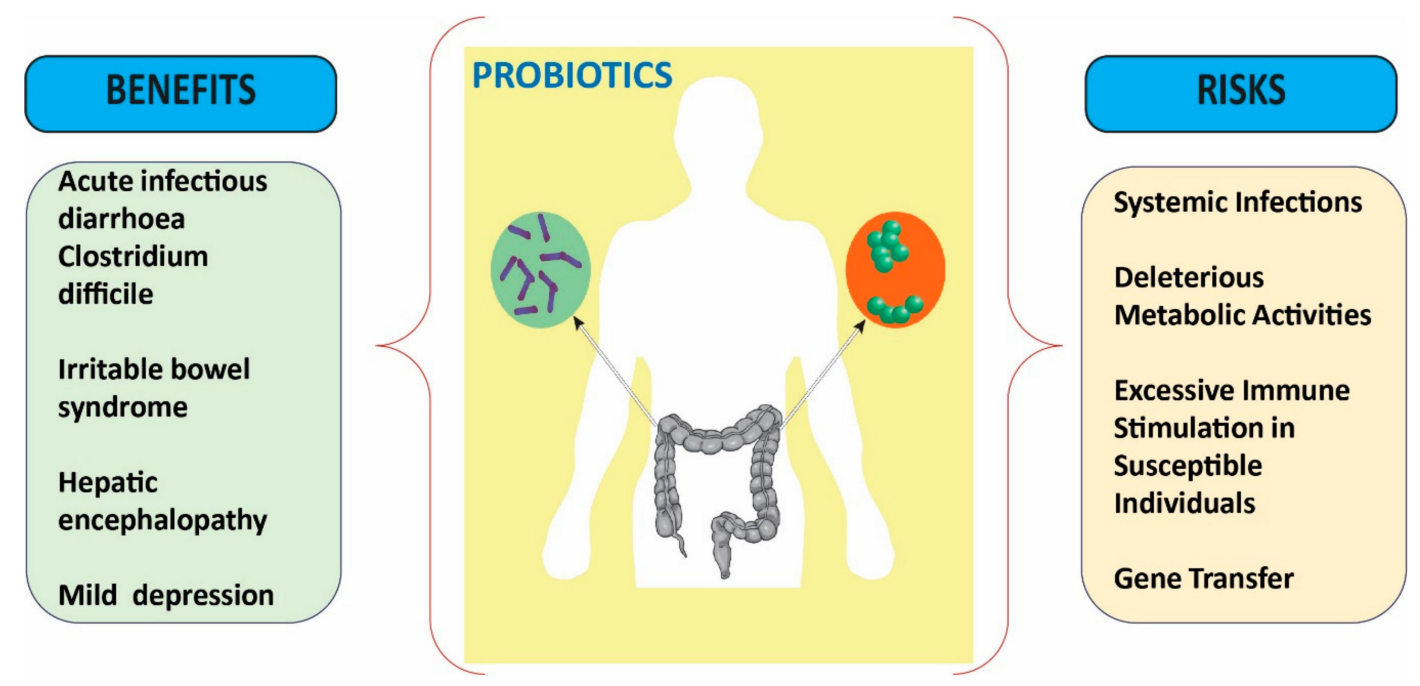

Figure 3. Summarized scheme of the benefits and risks of probiotics.

Hence, probiotics shall be evaluated at the strain level. For safety purposes, the FAO/WHO working group recommended that each probiotic strain shall be carefully assessed for toxin production ability, antibiotic resistance, and hemolytic potential, also determining its metabolic activity, and also considering their impact on humans, namely assessing its side effects and post-market surveillance aspects. Not least important is an assessment of their effects in immunocompromised animals, so as to obtain data on its ineffective potential in this type of host [20].

\subsection{Safety of Probiotics: Side Effects}

\subsubsection{Systemic Infections}

Several case reports describe episodes of infection caused by microorganisms considered as probiotics, e.g., fungemia, bacteremia, sepsis, endocarditis, and others. Fungemia is the most commonly reported single event, with at least 33 reports listing the presence of $S$. cerevisiae or $S$. boulardii in the blood cultures of patients who consumed S. boulardii. Bacteremia was reported in 8 cases consuming Lactobacilli, including L. acidophilus, L. casei, and L. rhamnosus. Overt sepsis was reported in 9 cases of those who consumed S. boulardii, L. rhamnosus, Bacillus subtilis, Bifidobacterium breve, or a probiotic combination $[141,142]$. Additionally, bacteremia resulting in endocarditis is one of the most important issues in probiotic strain safety. While the Lactobacillus infective endocarditis to total bacterial endocarditis ratio varies from 0.05 to $0.4 \%$, there are insufficient case reports in the literature on probiotic bacteremia. Lactobacillus-associated bacteremia mostly includes L. rhamnosus, $L$. plantarum, L. casei, L. paracasei, L. salivarius, and L. acidophilus [143]. Sanders et al. [144] described 3 
risk factors of probiotics identified in these patients: immunocompromised state, weakened intestinal barrier function, and use of a central venous catheter.

\subsubsection{Deleterious Metabolic Activities}

Lactobacillus are mostly associated to D-lactic acidosis, often found in patients with short bowel syndrome. In the case of a colonization with a high load of bacteria, they may lead to diarrhea and small bowel lesions, particularly by bile salt deconjugation and dehydroxylation [145]. In a study with patients with terminal ileostomy, it was stated that consuming fermented dairy products with L. acidophilus and Bifidobacterium, led to conjugated primary bile salt transformation into toxic free secondary ones through small bowel digestion [146].

In fact, secondary bile salts are dangerous elements, originated by intestinal bacteria on body secretions. These compounds may have carcinogenic potential through interacting with mucus-secreting cells, endorsing proliferation, or even acting as carcinogenesis-triggering agents [147]. There are numerous relevant bacterial enzymes in intestinal carcinogens and toxicant metabolisms (e.g., reductases and hydrolases). Nonetheless and importantly, Kumar et al. [148] showed that probiotics do not possess harmful biochemical activities, such as $\beta$-glucuronidase, $\alpha$-chymotrypsin, $\beta$-glucosidase, and $\mathrm{N}$-acetyl-ß-glycosaminidase, frequently related with intestinal disorders (e.g., carcinogens and tumor promoters).

Biogenic amines can be produced and degraded from natural metabolic activity in animals, plants, and microorganisms. Briefly, the elimination of the $\alpha$-carboxyl group from a precursor amino acid leads to a matching biogenic amine [124]. Occasional cases of food intoxication with histamine, tyrosine putrescine, and cadaverine activity have been credited to Lactobacillus [149].

\subsubsection{Excessive Immune Stimulation in Susceptible Individuals}

Probiotics exert a great influence in the immune system and also a theoretical risk of the potential immune system over-stimulation in susceptible subjects, which can lead to autoimmune response and inflammation. Though, these suppositions have not been long-established in humans [141].

\subsubsection{Gene Transfer}

It has been acknowledged that probiotic strains may be resistant to some antibiotics and can retain virulence factors and that transferable elements can set these resistances. Hence, there is, theoretically, the possibility of a lateral transfer of genes when using probiotics, which may spread to new and further virulent bacteria. Furthermore, lactic acid bacteria frequently anchor plasmids of diverse dimensions, and, in fact, certain antibiotic resistance determinants placed on plasmids have been found in L. lactis, and in several Lactobacillus and Enterococcus species [150].

So, it is essential to establish both the presence and transfer of bacterial resistance to control and prevent any antibiotic resistance cases [151]. Moreover, plasmid genes are accountable for functions such as bacteriocins production, carbohydrate metabolism, and also for conferring resistance to antibiotics of bacteria (e.g., PAM $\beta 1$ encodes resistance to macrolides, lincosamides and streptogramins (MLS)). This was noted in Enterococcus faecalis and its capability to transfer genes to other bacteria was confirmed with species of the Enterococcus, Staphylococcus, Clostridium, Lactobacillus, and Bacillus genera [152]. Likewise, numerous atypical antibiotic resistance-related genes have been listed amongst lactobacilli. For example, in L. acidophilus, L. delbrueckii subsp. bulgaricus, L. johnsonii, L. reuteri, and L. plantarum, chloramphenicol resistance genes (cat; chloramphenicol acetyltransferases) were detected.

Reports also demonstrated the presence of erythromycin resistance genes (responsible for MLS phenotype resistance), yet, the most common resistance genes found in lactobacilli were the tetracycline resistance genes, which typically occur in combination [153]. Infrequently, $\beta$-lactam, and aminoglycoside resistance genes have also been detected [154], and there has been no evidence of vancomycin resistance genes in Lactobacillus spp. 


\subsection{Quality Control of Probiotics}

When looking at the specific characteristics of a probiotic, formerly used as selection criteria, they also aim for quality assurance. The most prominent quality control criteria that must always be controlled and optimized include bile and acid stability; adhesive properties; manufacturing process' viability and survival; effects on carbohydrates, proteins, and fats; ability to colonize; and immunogenicity. Besides these properties, related to the physiologic properties of the strain, long-term industrial processing and storage conditions also affect probiotic quality. Thus, not only technologic but also functional properties should be considered in quality-control measures $[155,156]$.

Identification methods inappropriately used are a major cause of improper probiotic species designation and probiotic product labelling. These inconsistencies markedly affect probiotics' efficacy and safety and are likely to exert a negative impact on both health claims and consumer confidence [157].

Different phenotypic and genotypic approaches have been used on probiotic species and strain detection, identification, and characterization [158]. Briefly, nucleic acid-based genotypic approaches can be categorized into (1) hybridization-based techniques, (2) target amplification techniques, and (3) fingerprinting techniques, according to the methodologies used. Molecular techniques have also been used, but all have distinct strengths and weaknesses that consequently affect their applicability [157-160]. Nonetheless, the use of these techniques is mandatory because phenotypic identifications alone are not reliable enough.

First of all, probiotic strain identification is a critical step, as the correct identification is crucial for diagnostic and epidemiological purposes. Anyway, safety studies (pre-clinical and clinical studies) and those including taxonomy clarification and genome sequencing are also needed to ensure bacterial safety status [161].

\section{Discussion}

The most used probiotics contain strains of Bifidobacterium and Lactobacillus-the predominant groups of bacteria in the intestinal microbiota. The $S$. boulardii strain also showed beneficial effects. Thus, it is important to take into account the composition of the probiotic administered when interpreting the results on clinical safety and efficacy [162].

The effectiveness of probiotics depends on the species, dose and disease, and the duration of administration depends on the clinical indication. There is evidence that probiotics are effective in acute infectious diarrhea, diarrhea associated with antibiotic treatment, diarrhea associated with $C$. difficile infection, hepatic encephalopathy, ulcerative colitis, irritable bowel syndrome, functional GI disorders, and necrotizing enterocolitis. On the other hand, studies have shown a lack of efficacy in acute pancreatitis and Crohn's disease [163].

Probiotics help stimulate the synthesis of type A immunoglobulins, and this is the main mechanism by which probiotics are able to support immunity, i.e., to participate in immunomodulation. Studies document the increase in the general production of $\operatorname{IgA}$ as well as that of $\operatorname{Ig} \mathrm{A}$ specific to a certain pathogen, as a result of the interaction with probiotics. This action is an extremely important mechanism for anti-infective defense [89].

Studies tend to argue for the superior ability to stimulate $\operatorname{IgA}$ immunoglobulin synthesis of probiotic supplement formulas, especially when they are combined with prebiotics. In addition to supporting the synthesis of type A immunoglobulins, probiotics have also been shown to modulate the inflammatory processes and activity of natural killer NK cells, which fight virally infected and cancerous cells [164]. Moreover, probiotics increase the efficiency of the barrier function represented by the intestinal mucosa, therefore reducing the permeability induced by pathogenic microorganisms, but also that associated with inflammation [165].

To ensure health benefits, probiotics can be delivered through foods. A good example of functional food is a probiotic bacteria strains-rich product. The standard of a minimum level of viable probiotic cells ranging from $10^{6}$ to $10^{7} \mathrm{CFU} / \mathrm{mL}$ and the expiration date was also recommended [110]. However, the probiotics used in distinct food matrices is challenging. Distinct species display different sensitivities 
to substrate acidity, post-acidification in fermented products, dissolved oxygen, metabolism products, temperatures, and GI tract conditions. Bacteria viability and metabolic activity are key aspects on probiotic inclusion in a food raw material, as probiotic bacteria strains need to survive in the food matrix during the shelf life and GI digestion [7].

Dairy-fermented products (i.e., yogurt, probiotic beverages, and cheese-containing LAB) and their constituents (i.e., omega-3 fatty acid, phytosterols, isoflavones, conjugated linoleic acid (CLA), and minerals and vitamins) have a noticeable spot in functional foods formulation [117,166,167]. Moreover, the food industry has been increasingly devoted to the development of new non-dairy foods with probiotics able to surpass the restrictions (e.g., lactose intolerance and cholesterol content) inflicted by milk-based products, that limit their consumption by certain niches of the population [117].

Raw cured products have a very long tradition in Italy, Spain, Germany, France, Netherlands, Austria, and Belgium, with origins in Roman times in the Mediterranean area. Probiotic bacteria strains used in dry fermented meat product production must be able to survive in conditions found in fermented products. Moreover, they should dominate in relation to other microorganisms found in the finished product and need to be well-adapted to fermented product conditions. In a fermented meat environment, the selection of suitable microorganisms is critical because of cell viability, and is more likely strain-dependent [168]. Nonetheless, the probable negative effect on this viability must be valued, especially in the high content in curing salt, the low $\mathrm{pH}$ and water activity owed to acidification and drying [124,130]. Furthermore, the content and type of fats, proteins and sugars, and the product $\mathrm{pH}$ are features of extreme impact on probiotic growth and survival. Henceforward, product formulation should be manipulated to support a high probiotic efficacy [169]. In this sense, the selected strains to be used in fermented meat product manufacturing need to survive in fermented product conditions to reveal a good ability to adapt to real conditions, to survive fermentation and drying, refrigeration, and storage conditions, rather be able to grow until being able to display health-promoting effects and should have a central place, compared with other microorganisms found in the product (e.g., Lactobacillus spp. need close attention in meat fermentation and dry fermented sausage production) [124].

In April 2011, the Agency for Healthcare Research and Quality (AHRQ) of the U.S Department of Health and Human Services ("Safety of Probiotics to Reduce Risk and Prevent or Treat Disease") published a document evaluating probiotic safety. From 622 studies, in 235 of them merely non-specific safety statements were found, such as "well-tolerated", while in the remaining ones, the presence/absence of specific adverse events was listed. Built on these reported adverse events, although randomized controlled trials revealed no statistically significantly increase in the relative risk of experienced adverse events, other authors reported that rare adverse events are hard to evaluate [170].

Ideally, probiotic side effects should not exceed the placebo effect ("the zero risk does not exist, and that acceptance of the concept that probiotics may not only have positive effects but potentially also side effects is important") [171].

According to the FAO/WHO, probiotics may, theoretically, be responsible for 4 types of side effects [20]: systemic infections, deleterious metabolic activities, excessive immune stimulation in susceptible individuals, and, finally, gene transfer [141].

Despite the multiple options available and currently considered, a well-supported report of safe human consumption is the best test for food safety.

\section{Limitations and Clinical Pitfalls}

Evidence on the biological effect of probiotics (colonization of the intestinal mucosa) is limited and controversial. Two recent studies have provided new data showing that although probiotics remain viable throughout the GI tract, they manage to induce only a transient, variable, and individualized response to colonization of the intestinal mucosa [172]. 
Thus, a personalized, specific approach to the administration of probiotics would be necessary, as empirical supplementation with probiotics may not produce a uniform and persistent effect on the mucosa [173].

A disadvantage of probiotic dietary supplements is a form of preserving bacteria strain, mainly through the lyophilization or microencapsulation. There are many attempts to provide probiotics in the form of tablets, capsules, and lyophilized preparations [174].

Probiotic nutraceuticals have the disadvantage that they can lead to a reduction in functional efficiency due to the exclusion of the potential synergistic effect of food [175-178]. The alternative method uses starter cultures of probiotic properties in food production as received functional foods exhibit a high nutritional and sensory value. According to Conti-Silva et al. [178], the probiotic LAB contributes the desired odor and flavor of food stuffs through fermentation process, acidifying the products that presents a tangy lactic acid taste and producing aromatic sensory components from amino acids. What is also essential is the protective aspect of the food matrix, e.g., the media of living, active probiotic bacteria cells found within particular nutritional ingredients of food, including fat, sugar, or protein.

Probiotics have been found to delay the recovery of the gut microbiome. Probiotics were ineffective, much faster being the return to the initial state of the microbiome in those who did not take any treatment, as well as in those who received autologous fecal transplantation. Therefore, the context of probiotic use is crucial because, when taken after an antibiotic treatment, they have side effects.

Probiotics are generally considered safe, but caution should be exercised in immunologically vulnerable patients. The long-term effects of probiotic use are unknown and randomized studies are needed.

\section{Concluding Remarks}

Literature data indicate that supplementing a human diet with proper bacteria species showing proven probiotic properties enables a digestive tract to sustain its homeostasis, increasing the tolerance of an organism to unfavorable external stimuli. It facilitates the process of digestion and increases the assimilability of nutritional ingredients as well as shortening the span of recuperation when antibiotic treatment is necessary.

The beneficial effects of probiotics involve several mechanisms, including antagonistic action against specific microorganisms, reducing their number and their effects, direct effect on pathogens metabolism, and stimulating the host's immunity. Probiotics release antimicrobial and antibacterial agents, improving specific and nonspecific immunity, by activating macrophages, releasing cytokines, and increasing the level of immunoglobulins; ensures adequate intestinal $\mathrm{pH}$ by releasing butyric acid, lactic acid, and propionic acid; facilitates the digestion of proteins and lipids and improves lactose intolerance by producing lactase; and has competitive action with pathogens for nutrients and growth factors.

Studies have shown the beneficial roles of probiotics in the prevention and treatment of GI disorders, in the prevention of systemic infections, modulation of the immune system, prevention and treatment of allergies, and in moderating depression and anticarcinogenic effects.

The ideal probiotics should be non-toxic and non-pathogenic bacterial strains that adhere to the intestinal epithelium, thus exerting maximum beneficial effects on the human body. It must also survive in the digestive tract environment, preferably in large numbers, and be able to withstand a low $\mathrm{pH}$ and the action of bile salts. Other criteria that the probiotic agent must meet are the ability to produce antimicrobial agents, to modulate the immune system, and to influence the metabolism. Probiotics must be stable and withstand the technological processes of food preparation.

Author Contributions: All authors contributed to the manuscript. Conceptualization, N.M., J.S.-R.; validation investigation: C.F.R., Z.S.-R., M.D.; resources: A.A., K.N.-S., D.Z.; data curation: D.K.-K., B.S., S.M.P., F.S.; writing: all authors; review and editing, J.S.-R., A.O.D., N.M., D.C. All authors have read and agreed to the published version of the manuscript. 
Funding: This research received no external funding.

Acknowledgments: N.M. acknowledges the Portuguese Foundation for Science and Technology under the Horizon 2020 Program (PTDC/PSI-GER/28076/2017). C.F.R. acknowledges the UID/EQU/00511/2020 Project-Laboratory of Process Engineering, Environment, Biotechnology, and Energy_LEPABE financed by national funds through FCT/MCTES (PIDDAC).

Conflicts of Interest: The authors declare no conflict of interest.

\section{References}

1. Salehi, B.; Lopez-Jornet, P.; Pons-Fuster López, E.; Calina, D.; Sharifi-Rad, M.; Ramírez-Alarcón, K.; Forman, K.; Fernández, M.; Martorell, M.; Setzer, W.N. Plant-derived bioactives in oral mucosal lesions: A key emphasis to curcumin, lycopene, chamomile, aloe vera, green tea and coffee properties. Biomolecules 2019, 9, 106. [CrossRef]

2. Sharifi-Rad, M.; Kumar, N.V.A.; Zucca, P.; Varoni, E.M.; Dini, L.; Panzarini, E.; Rajkovic, J.; Tsouh Fokou, P.V.; Azzini, E.; Peluso, I.; et al. Lifestyle, oxidative stress and antioxidants: Back and forth in the pathophysiology of chronic diseases. Front. Physiol. 2020, 11, 694. [CrossRef] [PubMed]

3. Salehi, B.; Ata, A.; Kumar, N.V.A.; Sharopov, F.; Ramírez-Alarcón, K.; Ruiz-Ortega, A.; Ayatollahi, S.A.; Fokou, P.V.T.; Kobarfard, F.; Zakaria, Z.A.; et al. Antidiabetic potential of medicinal plants and their active components. Biomolecules 2019, 9, 551. [CrossRef] [PubMed]

4. Ayatollahi, A.M.; Ghanadian, M.; Afsharypuor, S.; Choudhary, M.I.; Kobarfard, F.; Rahmati, M. Two new lathyrane type diterpenoids from Euphorbia aellenii. Fitoterapia 2010, 81, 891-893. [CrossRef]

5. Choudhary, M.I.; Hussain, A.; Ali, Z.; Adhikari, A.; Sattar, S.A.; Ayatollahi, S.A.M.; Al-Majid, A.M.A.; Atta Ur, R. Diterpenoids including a novel dimeric conjugate from Salvia leriaefolia. Planta Med. 2012, 78, 269-275. [CrossRef] [PubMed]

6. Ayatollahi, A.M.; Ghanadian, M.; Afsharypuor, S.; Mesaik, M.A.; Abdalla, O.M.; Shahlaei, M.; Farzandi, G.; Mostafavi, H. Cycloartanes from Euphorbia aellenii Rech. f. and their Antiproliferative Activity. Iran. J. Pharm. Res. 2011, 10, 105-112.

7. Neffe-Skocińska, K.; Rzepkowska, A.; Szydłowska, A.; Kołożyn-Krajewska, D. Trends and possibilities of the use of probiotics in food production. In Alternative and Replacement Foods; Elsevier: Amsterdam, The Netherlands, 2018; pp. 65-94.

8. Russell, W.R.; Duncan, S.H. Advanced analytical methodologies to study the microbial metabolome of the human gut. TrAC Trends Anal. Chem. 2013, 52, 54-60. [CrossRef]

9. Tsoukalas, D.; Fragoulakis, V.; Sarandi, E.; Docea, A.O.; Papakonstantinou, E.; Tsilimidos, G.; Anamaterou, C.; Fragkiadaki, P.; Aschner, M.; Tsatsakis, A. Targeted metabolomic analysis of serum fatty acids for the prediction of autoimmune diseases. Front. Mol. Biosci. 2019, 6, 120. [CrossRef]

10. Tsoukalas, D.; Fragkiadaki, P.; Docea, A.O.; Alegakis, A.K.; Sarandi, E.; Vakonaki, E.; Salataj, E.; Kouvidi, E.; Nikitovic, D.; Kovatsi, L. Association of nutraceutical supplements with longer telomere length. Int. J. Mol. Med. 2019, 44, 218-226. [CrossRef]

11. Tsoukalas, D.; Fragkiadaki, P.; Docea, A.O.; Alegakis, A.K.; Sarandi, E.; Thanasoula, M.; Spandidos, D.A.; Tsatsakis, A.; Razgonova, M.P.; Calina, D. Discovery of potent telomerase activators: Unfolding new therapeutic and anti-aging perspectives. Mol. Med. Rep. 2019, 20, 3701-3708. [CrossRef]

12. Bagchi, T. Traditional food \& modern lifestyle: Impact of probiotics. Indian J. Med Res. 2014, 140, $333-335$.

13. Plaza-Diaz, J.; Ruiz-Ojeda, F.J.; Gil-Campos, M.; Gil, A. Mechanisms of action of probiotics. Adv. Nutr. 2019, 10, S49-S66. [CrossRef] [PubMed]

14. Ceccarelli, G.; Scagnolari, C.; Pugliese, F.; Mastroianni, C.M.; d'Ettorre, G. Probiotics and COVID-19. Lancet Gastroenterol. Hepatol. 2020, 5, 721-722. [CrossRef]

15. D’Ettorre, G.; Ceccarelli, G.; Marazzato, M.; Campagna, G.; Pinacchio, C.; Alessandri, F.; Ruberto, F.; Rossi, G.; Celani, L.; Scagnolari, C.; et al. Challenges in the management of SARS-CoV2 infection: The Role of oral bacteriotherapy as complementary therapeutic strategy to avoid the progression of COVID-19. Front. Med. (Lausanne) 2020, 7, 389. [CrossRef] [PubMed]

16. Kerry, R.G.; Patra, J.K.; Gouda, S.; Park, Y.; Shin, H.-S.; Das, G. Benefaction of probiotics for human health: A review. J. Food Drug Anal. 2018, 26, 927-939. [CrossRef] 
17. Rivera-Espinoza, Y.; Gallardo-Navarro, Y. Non-dairy probiotic products. Food Microbiol. 2010, $27,1-11$. [CrossRef] [PubMed]

18. Cinque, B.; La Torre, C.; Melchiorre, E.; Marchesani, G.; Zoccali, G.; Palumbo, P.; Di Marzio, L.; Masci, A.; Mosca, L.; Mastromarino, P. Use of probiotics for dermal applications. In Probiotics; Springer: New York, NY, USA, 2011; pp. 221-241.

19. Tripathi, M.; Giri, S. Probiotic functional foods: Survival of probiotics during processing and storage. J. Funct. Foods 2014, 9, 225-241. [CrossRef]

20. FAO; WHO. Joint FAO/WHO Working Group Report on Drafting Guidelines for the Evaluation of Probiotics in Food; FAO: London, ON, Canada; WHO: London, ON, Canada, 2002; Available online: http://www.who.int/ foodsafety/publications/fs_management/probiotics2/en/ (accessed on 24 December 2019).

21. Hill, C.; Guarner, F.; Reid, G.; Gibson, G.R.; Merenstein, D.J.; Pot, B.; Morelli, L.; Canani, R.B.; Flint, H.J.; Salminen, S. The international scientific association for probiotics and prebiotics consensus statement on the scope and appropriate use of the term probiotic. Nat. Rev. Gastroenterol. Hepatol. 2014, 11, 506-514. [CrossRef]

22. Peredo-Lovillo, A.; Romero-Luna, H.; Jiménez-Fernández, M. Health promoting microbial metabolites produced by gut microbiota after prebiotics metabolism. Food Res. Int. 2020, 136, 109473. [CrossRef]

23. Wang, S.; Xiao, Y.; Tian, F.; Zhao, J.; Zhang, H.; Zhai, Q.; Chen, W. Rational use of prebiotics for gut microbiota alterations: Specific bacterial phylotypes and related mechanisms. J. Funct. Foods 2020, 66, 103838. [CrossRef]

24. Mustafa, A.D.; Kalyanasundram, J.; Sabidi, S.; Song, A.A.-L.; Abdullah, M.; Rahim, R.A.; Yusoff, K. Recovery of recombinant Mycobacterium tuberculosis antigens fused with cell wall-anchoring motif (LysM) from inclusion bodies using non-denaturing reagent (N-laurylsarcosine). BMC Biotechnol. 2019, 19, 27. [CrossRef] [PubMed]

25. Pusceddu, M.M.; Murray, K.; Gareau, M.G. Targeting the microbiota, from irritable bowel syndrome to mood disorders: Focus on probiotics and prebiotics. Curr. Pathobiol. Rep. 2018, 6, 1-13. [CrossRef]

26. Kechagia, M.; Basoulis, D.; Konstantopoulou, S.; Dimitriadi, D.; Gyftopoulou, K.; Skarmoutsou, N.; Fakiri, E. Health benefits of probiotics: A review. ISRN Nutr. 2013, 2013, 481651. [CrossRef] [PubMed]

27. Wilkins, T.; Sequoia, J. Probiotics for gastrointestinal conditions: A summary of the evidence. Am. Fam. Physician 2017, 96, 170-178. [PubMed]

28. Islam, S.U. Clinical uses of probiotics. Medicine 2016, 95, e2658. [CrossRef] [PubMed]

29. Leung, A.K.; Leung, A.A.; Wong, A.H.; Hon, K.L. Travelers' diarrhea: A clinical review. Recent Pat. Inflamm. Allergy Drug Discov. 2019, 13, 38-48. [CrossRef]

30. Reid, G.; Jass, J.; Sebulsky, M.T.; McCormick, J.K. Potential uses of probiotics in clinical practice. Clin. Microbiol. Rev. 2003, 16, 658-672. [CrossRef]

31. do Espírito Santo, A.P.; Perego, P.; Converti, A.; Oliveira, M.N. Influence of food matrices on probiotic viability-A review focusing on the fruity bases. Trends Food Sci. Technol. 2011, 22, 377-385. [CrossRef]

32. Ołdak, A.; Zielińska, D.; Rzepkowska, A.; Kołożyn-Krajewska, D. Comparison of antibacterial activity of Lactobacillus plantarum strains isolated from two different kinds of regional cheeses from Poland: Oscypek and Korycinski cheese. BioMed Res. Int. 2017, 2017. [CrossRef]

33. Mantegazza, C.; Molinari, P.; D’Auria, E.; Sonnino, M.; Morelli, L.; Zuccotti, G.V. Probiotics and antibiotic-associated diarrhea in children: A review and new evidence on Lactobacillus rhamnosus GG during and after antibiotic treatment. Pharmacol. Res. 2018, 128, 63-72. [CrossRef]

34. Lee, Y.K. What could probiotic do for us? Food Sci. Hum. Wellness 2014, 3, 47-50. [CrossRef]

35. Benson, A.; Pifer, R.; Behrendt, C.L.; Hooper, L.V.; Yarovinsky, F. Gut commensal bacteria direct a protective immune response against Toxoplasma gondii. Cell Host Microbe 2009, 6, 187-196. [CrossRef]

36. Nowak, K.; Śliżewska, K.; Libudzisz, Z.; Socha, J. Probiotics-health effects. Żywność Nauka Technol. Jakość 2010, 4, 20-36.

37. Ungureanu, A.; Zlatian, O.; Mitroi, G.; Drocaş, A.; Țîrcă, T.; Călina, D.; Dehelean, C.; Docea, A.O.; Izotov, B.N.; Rakitskii, V.N. Staphylococcus aureus colonisation in patients from a primary regional hospital. Mol. Med. Rep. 2017, 16, 8771-8780. [CrossRef]

38. Călina, D.; Roșu, L.; Roșu, A.F.; Ianoşi, G.; Ianoşi, S.; Zlatian, O.; Mitruț, R.; Docea, A.; Rogoveanu, O.; Mitrut, P. Etiological diagnosis and pharmacotherapeutic management of parapneumonic pleurisy. Farmacia 2016, 64, 946-952. 
39. Tanase, A.; Colita, A.; Ianosi, G.; Neagoe, D.; Branisteanu, D.E.; Calina, D.; Docea, A.O.; Tsatsakis, A.; Ianosi, S.L. Rare case of disseminated fusariosis in a young patient with graft vs. host disease following an allogeneic transplant. Exp. Ther. Med. 2016, 12, 2078-2082. [CrossRef]

40. McFarland, L.; Evans, C.; Goldstein, E. Strain-specificity and disease-specificity of probiotic efficacy: A systematic review and meta-analysis. Front. Med. (Lausanne) 2018, 5, 124. [CrossRef]

41. Lü, M.; Yu, S.; Deng, J.; Yan, Q.; Yang, C.; Xia, G.; Zhou, X. Efficacy of probiotic supplementation therapy for Helicobacter pylori eradication: A meta-analysis of randomized controlled trials. PLoS ONE 2016, 11, e0163743. [CrossRef]

42. Rosu, A.; Patita, M.; Calina, D.; Andreea, N.; Fonseca, C. Multidrug resistant infections in cirrhosis patients. Filodiritto Editore. In Proceedings of the Romanian National Congress of Pharmacy, 17th Edition, Bucharest, Romania, 26-29 September 2018.

43. Jia, K.; Tong, X.; Wang, R.; Song, X. The clinical effects of probiotics for inflammatory bowel disease: A meta-analysis. Medicine (Baltimore) 2018, 97, e13792. [CrossRef]

44. Cho, S.J.; Kim, J.S.; Kim, J.M.; Lee, J.Y.; Jung, H.C.; Song, I.S. Simvastatin induces apoptosis in human colon cancer cells and in tumor xenografts, and attenuates colitis-associated colon cancer in mice. Int. J. Cancer 2008, 123, 951-957. [CrossRef]

45. Li, B.; Liang, L.; Deng, H.; Guo, J.; Shu, H.; Zhang, L. Efficacy and safety of probiotics in irritable bowel syndrome: A systematic review and meta-analysis. Front. Pharmacol. 2020, 11, 332. [CrossRef] [PubMed]

46. Choi, C.H.; Chang, S.K. Alteration of gut microbiota and efficacy of probiotics in functional constipation. J. Neurogastroenterol. Motil. 2015, 21, 4-7. [CrossRef] [PubMed]

47. AlFaleh, K.; Anabrees, J. Probiotics for prevention of necrotizing enterocolitis in preterm infants. Evid. Based Child Health A Cochrane Rev. J. 2014, 9, 584-671. [CrossRef] [PubMed]

48. Docea, A.O.; Gofiță, E.; Călina, D.; Zaharie, S.; Valcea, D.I.; Mitruț, P. Autoimmune disorders due to double antiviral therapy with Peginterferon and Ribavirin in patients with hepatitis $C$ virus infection. Farmacia 2016, 64, 605-611.

49. Xie, C.; Halegoua-DeMarzio, D. Role of probiotics in non-alcoholic fatty liver disease: Does gut microbiota matter? Nutrients 2019, 11, 2837. [CrossRef]

50. Shewry, P.R.; Hey, S.J. The contribution of wheat to human diet and health. Food Energy Secur. 2015, 4, 178-202. [CrossRef]

51. Scherf, K.A. Immunoreactive cereal proteins in wheat allergy, non-celiac gluten/wheat sensitivity (NCGS) and celiac disease. Curr. Opin. Food Sci. 2019, 25, 35-41. [CrossRef]

52. Akobeng, A.K.; Singh, P.; Kumar, M.; Al Khodor, S. Role of the gut microbiota in the pathogenesis of coeliac disease and potential therapeutic implications. Eur. J. Nutr. 2020, 1-22. [CrossRef]

53. Di Biase, A.R.; Marasco, G.; Ravaioli, F.; Dajti, E.; Colecchia, L.; Righi, B.; D'Amico, V.; Festi, D.; Iughetti, L.; Colecchia, A. Gut microbiota signatures and clinical manifestations in celiac disease children at onset: A pilot study. J. Gastroenterol. Hepatol. 2020. [CrossRef]

54. Valitutti, F.; Cucchiara, S.; Fasano, A. Celiac disease and the microbiome. Nutrients 2019, 11, 2403. [CrossRef]

55. Chibbar, R.; Dieleman, L.A. The gut microbiota in celiac disease and probiotics. Nutrients 2019, 11, 2375. [CrossRef] [PubMed]

56. Galipeau, H.J.; McCarville, J.L.; Huebener, S.; Litwin, O.; Meisel, M.; Jabri, B.; Sanz, Y.; Murray, J.A.; Jordana, M.; Alaedini, A.; et al. Intestinal microbiota modulates gluten-induced immunopathology in humanized mice. Am. J. Pathol. 2015, 185, 2969-2982. [CrossRef] [PubMed]

57. Henggeler, J.C.; Veríssimo, M.; Ramos, F. Non-coeliac gluten sensitivity: A review of the literature. Trends Food Sci. Technol. 2017, 66, 84-92. [CrossRef]

58. Mahdavinia, M. Food allergy in adults: Presentations, evaluation, and treatment. Med. Clin. 2020, 104, 145-155.

59. Morais, S.; Tortajada-Genaro, L.A.; Maquieira, A.; Martinez, M.-A.G. Biosensors for food allergy detection according to specific IgE levels in serum. TrAC Trends Anal. Chem. 2020, 127, 115904. [CrossRef]

60. Lee, K.H.; Song, Y.; Wu, W.; Yu, K.; Zhang, G. The gut microbiota, environmental factors, and links to the development of food allergy. Clin. Mol. Allergy 2020, 18,1-11. [CrossRef]

61. Schülke, S.; Albrecht, M. Mouse models for food allergies: Where do we stand? Cells 2019, 8, 546. [CrossRef] 
62. Aitoro, R.; Paparo, L.; Amoroso, A.; Di Costanzo, M.; Cosenza, L.; Granata, V.; Di Scala, C.; Nocerino, R.; Trinchese, G.; Montella, M.; et al. Gut Microbiota as a target for preventive and therapeutic intervention against food allergy. Nutrients 2017, 9, 672. [CrossRef]

63. Stefka, A.T.; Feehley, T.; Tripathi, P.; Qiu, J.; McCoy, K.; Mazmanian, S.K.; Tjota, M.Y.; Seo, G.-Y.; Cao, S.; Theriault, B.R. Commensal bacteria protect against food allergen sensitization. Proc. Natl. Acad. Sci. USA 2014, 111, 13145-13150. [CrossRef]

64. Boynton, W.; Floch, M. New strategies for the management of diverticular disease: Insights for the clinician. Ther. Adv. Gastroenterol. 2013, 6, 205-213. [CrossRef]

65. Scarpignato, C.; Bertelé, A.; Tursi, A. Probiotics for the Treatment of symptomatic uncomplicated diverticular disease: Rationale and current evidence. J. Clin. Gastroenterol. 2016, 50 (Suppl. 1), S70-S73. [CrossRef]

66. Lahner, E.; Bellisario, C.; Hassan, C.; Zullo, A.; Esposito, G.; Annibale, B. Probiotics in the Treatment of diverticular disease: A systematic review. J. Gastrointestin. Liver Dis. 2016, 25, 79-86. [CrossRef]

67. Rondanelli, M.; Faliva, M.A.; Perna, S.; Giacosa, A.; Peroni, G.; Castellazzi, A.M. Using probiotics in clinical practice: Where are we now? A review of existing meta-analyses. Gut Microbes 2017, 8, 521-543. [CrossRef] [PubMed]

68. Bogdan, M.; Gofita, E.; Calina, D.C.; Turcu-Stiolica, A.; Docea, A.O.; Balseanu, T.A.; Camen, A.; Popa, G.E.; Rusu, G.; Cristofor, I. New antidepressant medication: Benefits versus adverse effects. In Pharmacokinetics and Adverse Effects of Drugs-Mechanisms and Risks Factors; IntechOpen: Rijeka, Croatia, 2017.

69. Nussbaum, L.; Hogea, L.M.; Călina, D.; Andreescu, N.; Grădinaru, R.; Ștefănescu, R.; Puiu, M. Modern treatment approaches in psychoses. Pharmacogenetic, neuroimagistic and clinical implications. Farmacia 2017, 65, 75-81.

70. Sharifi-Rad, M.; Lankatillake, C.; Dias, D.A.; Docea, A.O.; Mahomoodally, M.F.; Lobine, D.; Chazot, P.L.; Kurt, B.; Boyunegmez Tumer, T.; Catarina Moreira, A. Impact of natural compounds on neurodegenerative disorders: From preclinical to pharmacotherapeutics. J. Clin. Med. 2020, 9, 1061. [CrossRef] [PubMed]

71. Wallace, C.J.K.; Milev, R. The effects of probiotics on depressive symptoms in humans: A systematic review. Ann. Gen. Psychiatry 2017, 16, 14. [CrossRef]

72. Gayathri, D.; Rashmi, B. Anti-cancer properties of probiotics: A natural strategy for cancer prevention. EC Nutr. 2016, 5, 1191-1202.

73. Bozkurt, H. Utilization of natural antioxidants: Green tea extract and Thymbra spicata oil in Turkish dry-fermented sausage. Meat Sci. 2006, 73, 442-450. [CrossRef]

74. Honikel, K.-O. The use and control of nitrate and nitrite for the processing of meat products. Meat Sci. 2008, 78, 68-76. [CrossRef]

75. Eusebi, L.H.; Telese, A.; Marasco, G.; Bazzoli, F.; Zagari, R.M. Gastric cancer prevention strategies: A global perspective. J. Gastroenterol. Hepatol. 2020. [CrossRef]

76. Neffe-Skocińska, K.; Okoń, A.; Kołożyn-Krajewska, D.; Dolatowski, Z. Amino acid profile and sensory characteristics of dry fermented pork loins produced with a mixture of probiotic starter cultures. J. Sci. Food Agric. 2017, 97, 2953-2960. [CrossRef]

77. Azad, M.; Kalam, A.; Sarker, M.; Wan, D. Immunomodulatory effects of probiotics on cytokine profiles. BioMed Res. Int. 2018, 2018, 8063647. [CrossRef]

78. Davani-Davari, D.; Negahdaripour, M.; Karimzadeh, I.; Seifan, M.; Mohkam, M.; Masoumi, S.J.; Berenjian, A.; Ghasemi, Y. Prebiotics: Definition, types, sources, mechanisms, and clinical applications. Foods 2019, 8, 92. [CrossRef]

79. Rodrigues, C.F.; Rodrigues, M.E.; Henriques, M.C. Promising alternative therapeutics for oral candidiasis. Curr. Med. Chem. 2019, 26, 2515-2528. [CrossRef]

80. Sela, D.; Chapman, J.; Adeuya, A.; Kim, J.; Chen, F.; Whitehead, T.; Lapidus, A.; Rokhsar, D.; Lebrilla, C.B.; German, J. The genome sequence of Bifidobacterium longum subsp. infantis reveals adaptations for milk utilization within the infant microbiome. Proc. Natl. Acad. Sci. USA 2008, 105, 18964-18969. [CrossRef]

81. Akelma, A.Z.; Topcu, Z. Probiotics and allergic disease. World J. Immunol. 2016, 6, 75-82. [CrossRef]

82. Calina, D.; Docea, A.O.; Golokhvast, K.S.; Sifakis, S.; Tsatsakis, A.; Makrigiannakis, A. Management of endocrinopathies in pregnancy: A review of current evidence. Int. J. Environ. Res. Public Health 2019, $16,781$. [CrossRef]

83. Song, S.; Lee, S.-J.; Park, D.-J.; Oh, S.; Lim, K.-T. The anti-allergic activity of Lactobacillus plantarum L67 and its application to yogurt. J. Dairy Sci. 2016, 99, 9372-9382. [CrossRef] 
84. Ganguli, K.; Collado, M.C.; Rautava, J.; Lu, L.; Satokari, R.; von Ossowski, I.; Reunanen, J.; de Vos, W.M.; Palva, A.; Isolauri, E.; et al. Lactobacillus rhamnosus GG and its SpaC pilus adhesin modulate inflammatory responsiveness and TLR-related gene expression in the fetal human gut. Pediatr. Res. 2015, 77, 528-535. [CrossRef]

85. Llewellyn, A.; Foey, A. Probiotic modulation of innate cell pathogen sensing and signaling events. Nutrients 2017, 9, 1156. [CrossRef] [PubMed]

86. Rask, C.; Adlerberth, I.; Berggren, A.; Ahrén, I.L.; Wold, A.E. Differential effect on cell-mediated immunity in human volunteers after intake of different lactobacilli. Clin. Exp. Immunol. 2013, 172, 321-332. [CrossRef] [PubMed]

87. Vitetta, L.; Saltzman, E.T.; Thomsen, M.; Nikov, T.; Hall, S. Adjuvant probiotics and the intestinal microbiome: Enhancing vaccines and immunotherapy outcomes. Vaccines 2017, 5, 50. [CrossRef]

88. Biswas, G.; Korenaga, H.; Nagamine, R.; Kawahara, S.; Takeda, S.; Kikuchi, Y.; Dashnyam, B.; Yoshida, T.; Kono, T.; Sakai, M. Elevated cytokine responses to Vibrio harveyi infection in the Japanese pufferfish (Takifugu rubripes) treated with Lactobacillus paracasei spp. paracasei (06TCa22) isolated from the Mongolian dairy product. Fish Shellfish Immunol. 2013, 35, 756-765. [CrossRef] [PubMed]

89. Galdeano, C.M.; Cazorla, S.I.; Dumit, J.M.L.; Vélez, E.; Perdigón, G. Beneficial effects of probiotic consumption on the immune system. Ann. Nutr. Metab. 2019, 74, 115-124.

90. Docea, A.O.; Tsatsakis, A.; Albulescu, D.; Cristea, O.; Zlatian, O.; Vinceti, M.; Moschos, S.A.; Tsoukalas, D.; Goumenou, M.; Drakoulis, N. A new threat from an old enemy: Re-emergence of coronavirus. Int. J. Mol. Med. 2020, 45, 1631-1643. [CrossRef]

91. Calina, D.; Docea, A.O.; Petrakis, D.; Egorov, A.M.; Ishmukhametov, A.A.; Gabibov, A.G.; Shtilman, M.I.; Kostoff, R.; Carvalho, F.; Vinceti, M. Towards effective COVID-19 vaccines: Updates, perspectives and challenges. Int. J. Mol. Med. 2020, 46, 3-16. [CrossRef]

92. Islam, M.T.; Nasiruddin, M.; Khan, I.N.; Mishra, S.K.; Kudrat-E-Zahan, M.; Riaz, T.A.; Ali, E.S.; Rahman, M.S.; Mubarak, M.S.; Martorell, M.; et al. A perspective on emerging therapeutic interventions for COVID-19. Front. Public Health 2020, 8, 281. [CrossRef] [PubMed]

93. Wojewodzic, M.W. Bacteriophages could be a potential game changer in the trajectory of coronavirus disease (COVID-19). PHAGE 2020, 1, 60-65. [CrossRef]

94. Dhar, D.; Mohanty, A. Gut microbiota and Covid-19-possible link and implications. Virus Res. 2020, 285, 198018. [CrossRef]

95. Hall, A.B.; Tolonen, A.C.; Xavier, R.J. Human genetic variation and the gut microbiome in disease. Nat. Rev. Genet. 2017, 18, 690-699. [CrossRef]

96. Infusino, F.; Marazzato, M.; Mancone, M.; Fedele, F.; Mastroianni, C.M.; Severino, P.; Ceccarelli, G.; Santinelli, L.; Cavarretta, E.; Marullo, A.G.M.; et al. Diet supplementation, probiotics, and nutraceuticals in SARS-CoV-2 infection: A scoping review. Nutrients 2020, 12, 1718. [CrossRef] [PubMed]

97. Liévin-Le Moal, V.; Servin, A.L. Anti-infective activities of lactobacillus strains in the human intestinal microbiota: From probiotics to gastrointestinal anti-infectious biotherapeutic agents. Clin. Microbiol. Rev. 2014, 27, 167-199. [CrossRef] [PubMed]

98. Kim, Y.K.; Shin, C. The microbiota-gut-brain axis in neuropsychiatric disorders: Pathophysiological mechanisms and novel treatments. Curr. Neuropharmacol. 2018, 16, 559-573. [CrossRef]

99. Barzegari, A.; Kheyrolahzadeh, K.; Hosseiniyan Khatibi, S.M.; Sharifi, S.; Memar, M.Y.; Zununi Vahed, S. The battle of probiotics and their derivatives against biofilms. Infect. Drug Resist. 2020, 13, 659-672. [CrossRef]

100. Petrakis, D.; Margină, D.; Tsarouhas, K.; Tekos, F.; Stan, M.; Nikitovic, D.; Kouretas, D.; Spandidos, D.A.; Tsatsakis, A. Obesity-A risk factor for increased COVID-19 prevalence, severity and lethality (Review). Mol. Med. Rep. 2020, 22, 9-19. [CrossRef] [PubMed]

101. Sharifi-Rad, J.; Rodrigues, C.F.; Sharopov, F.; Docea, A.O.; Can Karaca, A.; Sharifi-Rad, M.; Kahveci Karıncaoglu, D.; Gülseren, G.; Şenol, E.; Demircan, E. Diet, lifestyle and cardiovascular diseases: Linking pathophysiology to cardioprotective effects of natural bioactive compounds. Int. J. Environ. Res. Public Health 2020, 17, 2326. [CrossRef] [PubMed]

102. Tian, Y.; Xu, B.; Yu, D.; Ma, Y.; Wang, Y.; Jiang, Y.; Hu, W.; Tang, C.; Gao, Y.; Luo, K. Ultrahard nanotwinned cubic boron nitride. Nature 2013, 493, 385-388. [CrossRef] [PubMed]

103. Lozupone, C.A.; Stombaugh, J.I.; Gordon, J.I.; Jansson, J.K.; Knight, R. Diversity, stability and resilience of the human gut microbiota. Nature 2012, 489, 220-230. [CrossRef] 
104. Trinchieri, V.; Laghi, L.; Vitali, B.; Parolin, C.; Giusti, I.; Capobianco, D.; Mastromarino, P.; De Simone, C. Efficacy and safety of a multistrain probiotic formulation depends from manufacturing. Front. Immunol. 2017, 8, 1474. [CrossRef]

105. Timmerman, H.; Koning, C.; Mulder, L.; Rombouts, F.; Beynen, A. Monostrain, multistrain and multispecies probiotics-A comparison of functionality and efficacy. Int. J. Food Microbiol. 2004, 96, 219-233. [CrossRef]

106. Conde-Islas, A.Á.; Jiménez-Fernández, M.; Cantú-Lozano, D.; Urrea-García, G.R.; Luna-Solano, G. Effect of the freeze-drying process on the physicochemical and microbiological properties of mexican kefir grains. Processes 2019, 7, 127. [CrossRef]

107. De Simone, C. The unregulated probiotic market. Clin. Gastroenterol. Hepatol. 2019, 17, 809-817. [CrossRef] [PubMed]

108. Cinque, B.; La Torre, C.; Lombardi, F.; Palumbo, P.; Evtoski, Z.; Santini, S., Jr.; Falone, S.; Cimini, A.; Amicarelli, F.; Cifone, M.G. VSL\# 3 probiotic differently influences IEC-6 intestinal epithelial cell status and function. J. Cell. Physiol. 2017, 232, 3530-3539. [PubMed]

109. Gareau, M.G.; Sherman, P.M.; Walker, W.A. Probiotics and the gut microbiota in intestinal health and disease. Nat. Rev. Gastroenterol. Hepatol. 2010, 7, 503-514. [CrossRef] [PubMed]

110. Shori, A.B. Influence of food matrix on the viability of probiotic bacteria: A review based on dairy and non-dairy beverages. Food Biosci. 2016, 13, 1-8. [CrossRef]

111. Hu, C.; Wong, F.S.; Wen, L. Type 1 diabetes and gut microbiota: Friend or foe? Pharmacol. Res. 2015, 98, 9-15. [CrossRef]

112. Iqbal, M.Z.; Qadir, M.I.; Hussain, T.; Janbaz, K.H.; Khan, Y.H.; Ahmad, B. Probiotics and their beneficial effects against various diseases. Pak. J. Pharm. Sci. 2014, 27, 405-415.

113. Barrett, H.L.; Callaway, L.K.; Nitert, M.D. Probiotics: A potential role in the prevention of gestational diabetes? Acta Diabetol. 2012, 49, 1-13. [CrossRef]

114. Xu, Y.-J. Foodomics: A novel approach for food microbiology. TrAC Trends Anal. Chem. 2017, 96, 14-21. [CrossRef]

115. David, L.A.; Maurice, C.F.; Carmody, R.N.; Gootenberg, D.B.; Button, J.E.; Wolfe, B.E.; Ling, A.V.; Devlin, A.S.; Varma, Y.; Fischbach, M.A. Diet rapidly and reproducibly alters the human gut microbiome. Nature 2014, 505, 559-563. [CrossRef]

116. Terpou, A.; Papadaki, A.; Lappa, I.K.; Kachrimanidou, V.; Bosnea, L.A.; Kopsahelis, N. Probiotics in food systems: Significance and emerging strategies towards improved viability and delivery of enhanced beneficial value. Nutrients 2019, 11, 1591. [CrossRef] [PubMed]

117. Mishra, S.; Mishra, H. Technological aspects of probiotic functional food development. Nutrafoods 2012, 11, 117-130. [CrossRef]

118. Botta, C.; Bertolino, M.; Zeppa, G.; Cocolin, L. Evaluation of toma piemontese PDO cheese as a carrier of putative probiotics from table olive fermentations. J. Funct. Foods 2015, 18, 106-116. [CrossRef]

119. Sanders, M.E.; Klaenhammer, T.R.; Ouwehand, A.C.; Pot, B.; Johansen, E.; Heimbach, J.T.; Marco, M.L.; Tennilä, J.; Ross, R.P.; Franz, C. Effects of genetic, processing, or product formulation changes on efficacy and safety of probiotics. Ann. N. Y. Acad. Sci. 2014, 1309, 1-18. [CrossRef] [PubMed]

120. Neffe, K.; Kolozyn-Krajewska, D. Potential uses of probiotic bacteria in ripening meat products. Zywnosc Nauka Technol. Jakosc (Poland) 2010, 17, 167-177.

121. Neffe-Skocinska, K.; Gierejkiewicz, M.; Kolozyn-Krajewska, D. Optimization of fermentation conditions for dry-aged sirloins with probiotic bacteria added. Zywnosc Nauka Technol. Jakosc 2011, 18, 36-46. [CrossRef]

122. Wójciak, K.; Dolatowski, Z.; Okon, A. The effect of probiotic strains on oxidative stability of cured pork meat products. Fleischwirtschaft 2012, 1, 100-104.

123. Yeo, S.-K.; Ewe, J.-A.; Tham, C.S.-C.; Liong, M.-T. Carriers of probiotic microorganisms. In Probiotics; Springer: New York, NY, USA, 2011; pp. 191-220.

124. Kołożyn-Krajewska, D.; Dolatowski, Z.J. Probiotic meat products and human nutrition. Process Biochem. 2012, 47, 1761-1772. [CrossRef]

125. Klingberg, T.D.; Axelsson, L.; Naterstad, K.; Elsser, D.; Budde, B.B. Identification of potential probiotic starter cultures for Scandinavian-type fermented sausages. Int. J. Food Microbiol. 2005, 105, 419-431. [CrossRef]

126. Erkkila, S.; Suihko, M.L.; Eerola, S.; Petaja, E.; Mattila-Sandholm, T. Dry sausage fermented by Lactobacillus rhamnosus strains. Int. J. Food Microbiol. 2001, 64, 205-210. [CrossRef] 
127. Holko, I.; Hrabě, J.; Šalaková, A.; Rada, V. The substitution of a traditional starter culture in mutton fermented sausages by Lactobacillus acidophilus and Bifidobacterium animalis. Meat Sci. 2013, 94, 275-279. [CrossRef] [PubMed]

128. Arihara, K.; Itoh, M. UV-induced Lactobacillus gasseri mutants resisting sodium chloride and sodium nitrite for meat fermentation. Int. J. Food Microbiol. 2000, 56, 227-230. [CrossRef]

129. Muthukumarasamy, P.; Holley, R.A. Survival of Escherichia coli O157: H7 in dry fermented sausages containing micro-encapsulated probiotic lactic acid bacteria. Food Microbiol. 2007, 24, 82-88. [CrossRef] [PubMed]

130. Toldrá, F.; Reig, M. Innovations for healthier processed meats. Trends Food Sci. Technol. 2011, $22,517-522$. [CrossRef]

131. Kumar, B.V.; Vijayendra, S.V.N.; Reddy, O.V.S. Trends in dairy and non-dairy probiotic products-a review. J. Food Sci. Technol. 2015, 52, 6112-6124. [CrossRef]

132. Ouwehand, A.C.; Kurvinen, T.; Rissanen, P. Use of a probiotic Bifidobacterium in a dry food matrix, an in vivo study. Int. J. Food Microbiol. 2004, 95, 103-106. [CrossRef]

133. Salehi, B.; Capanoglu, E.; Adrar, N.; Catalkaya, G.; Shaheen, S.; Jaffer, M.; Giri, L.; Suyal, R.; Jugran, A.K.; Calina, D. Cucurbits plants: A key emphasis to its pharmacological potential. Molecules 2019, 24, 1854. [CrossRef]

134. Salehi, B.; Sharifi-Rad, J.; Capanoglu, E.; Adrar, N.; Catalkaya, G.; Shaheen, S.; Jaffer, M.; Giri, L.; Suyal, R.; Jugran, A.K. Cucurbita plants: From farm to industry. Appl. Sci. 2019, 9, 3387. [CrossRef]

135. Salehi, B.; Shivaprasad Shetty, M.; V Anil Kumar, N.; Živković, J.; Calina, D.; Oana Docea, A.; Emamzadeh-Yazdi, S.; Sibel Kılıç, C.; Goloshvili, T.; Nicola, S. Veronica plants-Drifting from farm to traditional healing, food application, and phytopharmacology. Molecules 2019, 24, 2454. [CrossRef]

136. Batista, C.; Barros, L.; Carvalho, A.M.; Ferreira, I.C. Nutritional and nutraceutical potential of rape (Brassica napus L. var. napus) and "tronchuda" cabbage (Brassica oleraceae L. var. costata) inflorescences. Food Chem. Toxicol. 2011, 49, 1208-1214.

137. Jaiswal, A.K.; Abu-Ghannam, N. Kinetic studies for the preparation of probiotic cabbage juice: Impact on phytochemicals and bioactivity. Ind. Crops Prod. 2013, 50, 212-218. [CrossRef]

138. Possemiers, S.; Marzorati, M.; Verstraete, W.; Van de Wiele, T. Bacteria and chocolate: A successful combination for probiotic delivery. Int. J. Food Microbiol. 2010, 141, 97-103. [CrossRef] [PubMed]

139. Venugopalan, V.; Shriner, K.A.; Wong-Beringer, A. Regulatory oversight and safety of probiotic use. Emerg. Infect. Dis. 2010, 16, 1661-1665. [CrossRef] [PubMed]

140. Hoffmann, D.E.; Fraser, C.; Palumbo, F.; Ravel, F.; Rowthorn, J.; Schwartz, V. Final Report. Federal Regulation of Probiotics: An Analysis of the Existing Regulatory Framework and Recommendations for Alternative Frameworks; White Paper; University Maryland Francis King Carey School of Law: Baltimore, MD, USA, 2016; Available online: http://www.law.umaryland.edu (accessed on 18 January 2020).

141. Doron, S.; Snydman, D.R. Risk and safety of probiotics. Clin. Infect. Dis. 2015, 60, S129-S134. [CrossRef] [PubMed]

142. Whelan, K.; Myers, C.E. Safety of probiotics in patients receiving nutritional support: A systematic review of case reports, randomized controlled trials, and nonrandomized trials. Am. J. Clin. Nutr. 2010, 91, 687-703. [CrossRef]

143. Bernardeau, M.; Guguen, M.; Vernoux, J.P. Beneficial lactobacilli in food and feed: Long-term use, biodiversity and proposals for specific and realistic safety assessments. FEMS Microbiol. Rev. 2006, 30, 487-513. [CrossRef]

144. Sanders, M.E.; Akkermans, L.M.; Haller, D.; Hammerman, C.; Heimbach, J.T.; Hörmannsperger, G.; Huys, G. Safety assessment of probiotics for human use. Gut Microbes 2010, 1, 164-185. [CrossRef]

145. Munakata, S.; Arakawa, C.; Kohira, R.; Fujita, Y.; Fuchigami, T.; Mugishima, H. A case of D-lactic acid encephalopathy associated with use of probiotics. Brain Dev. 2010, 32, 691-694. [CrossRef]

146. Ruseler-van Embden, J.; Van Lieshout, L.; Gosselink, M.; Marteau, P. Inability of Lactobacillus casei strain GG, L. acidophilus, and Bifidobacterium bifidum to degrade intestinal mucus glycoproteins. Scand. J. Gastroenterol. 1995, 30, 675-680. [CrossRef]

147. Ridlon, J.M.; Wolf, P.G.; Gaskins, H.R. Taurocholic acid metabolism by gut microbes and colon cancer. Gut Microbes 2016, 7, 201-215. [CrossRef]

148. Kumar, M.; Ghosh, M.; Ganguli, A. Mitogenic response and probiotic characteristics of lactic acid bacteria isolated from indigenously pickled vegetables and fermented beverages. World J. Microbiol. Biotechnol. 2012, 28, 703-711. [CrossRef] [PubMed] 
149. O'Brien, J.; Crittenden, R.; Ouwehand, A.C.; Salminen, S. Safety evaluation of probiotics. Trends Food Sci. Technol. 1999, 10, 418-424. [CrossRef]

150. Cui, Y.; Hu, T.; Qu, X.; Zhang, L.; Ding, Z.; Dong, A. Plasmids from food lactic acid bacteria: Diversity, similarity, and new developments. Int. J. Mol. Sci. 2015, 16, 13172-13202. [CrossRef] [PubMed]

151. Franz, C.M.; Huch, M.; Abriouel, H.; Holzapfel, W.; Gálvez, A. Enterococci as probiotics and their implications in food safety. Int. J. Food Microbiol. 2011, 151, 125-140. [CrossRef] [PubMed]

152. Sharma, P.; Tomar, S.K.; Goswami, P.; Sangwan, V.; Singh, R. Antibiotic resistance among commercially available probiotics. Food Res. Int. 2014, 57, 176-195. [CrossRef]

153. Ammor, M.S.; Flórez, A.B.; Van Hoek, A.H.; Clara, G.; Aarts, H.J.; Margolles, A.; Mayo, B. Molecular characterization of intrinsic and acquired antibiotic resistance in lactic acid bacteria and bifidobacteria. $J$. Mol. Microbiol. Biotechnol. 2008, 14, 6-15. [CrossRef]

154. Gueimonde, M.; Sanchez, B.; de los Reyes-Gavilan, C.G.; Margolles, A. Antibiotic resistance in probiotic bacteria. Front. Microbiol. 2013, 4, 202.

155. Tuomola, E.; Crittenden, R.; Playne, M.; Isolauri, E.; Salminen, S. Quality assurance criteria for probiotic bacteria. Am. J. Clin. Nutr. 2001, 73, 393s-398s. [CrossRef]

156. Georgieva, M.; Andonova, L.; Peikova, L.; Zlatkov, A. Probiotics-Health benefits, classification, quality assurance and quality control-Review. Pharmacia 2014, 61, 22-31.

157. Huys, G.; Botteldoorn, N.; Delvigne, F.; De Vuyst, L.; Heyndrickx, M.; Pot, B.; Dubois, J.J.; Daube, G. Microbial characterization of probiotics-Advisory report of the working group "8651 probiotics" of the Belgian superior health council (SHC). Mol. Nutr. Food Res. 2013, 57, 1479-1504. [CrossRef]

158. Mianzhi, Y.; Shah, N.P. Contemporary nucleic acid-based molecular techniques for detection, identification, and characterization of Bifidobacterium. Crit. Rev. Food Sci. Nutr. 2017, 57, 987-1016. [CrossRef] [PubMed]

159. Holzapfel, W.H.; Haberer, P.; Geisen, R.; Björkroth, J.; Schillinger, U. Taxonomy and important features of probiotic microorganisms in food and nutrition. Am. J. Clin. Nutr. 2001, 73, 365s-373s. [CrossRef] [PubMed]

160. Chandok, H.; Shah, P.; Akare, U.R.; Hindala, M.; Bhadoriya, S.S.; Ravi, G.; Sharma, V.; Bandaru, S.; Rathore, P.; Nayarisseri, A. Screening, isolation and identification of probiotic producing lactobacillus acidophilus strains EMBS081 \& EMBS082 by 16S rRNA gene sequencing. Interdiscip. Sci. Comput. Life Sci. 2015, 7, 242-248.

161. Shokryazdan, P.; Faseleh Jahromi, M.; Liang, J.B.; Ho, Y.W. Probiotics: From isolation to application. J. Am. Coll. Nutr. 2017, 36, 666-676. [CrossRef]

162. Wosinska, L.; Cotter, P.D.; O'Sullivan, O.; Guinane, C. The potential impact of probiotics on the gut microbiome of athletes. Nutrients 2019, 11, 2270. [CrossRef]

163. Ritchie, M.L.; Romanuk, T.N. A meta-analysis of probiotic efficacy for gastrointestinal diseases. PLoS ONE 2012, 7, e34938. [CrossRef]

164. Da Silva, T.F.; Casarotti, S.N.; de Oliveira, G.L.V.; Penna, A.L.B. The impact of probiotics, prebiotics, and synbiotics on the biochemical, clinical, and immunological markers, as well as on the gut microbiota of obese hosts. Crit. Rev. Food Sci. Nutr. 2020, 1-19. [CrossRef] [PubMed]

165. Bron, P.A.; Kleerebezem, M.; Brummer, R.J.; Cani, P.D.; Mercenier, A.; MacDonald, T.T.; Garcia-Ródenas, C.L.; Wells, J.M. Can probiotics modulate human disease by impacting intestinal barrier function? Br. J. Nutr. 2017, 117, 93-107. [CrossRef]

166. Bogsan, C.S.B.; Ferreira, L.; Maldonado, C.; Perdigon, G.; Almeida, S.R.d.; Oliveira, M.N.d. Fermented or unfermented milk using Bifidobacterium animalis subsp. lactis HN019: Technological approach determines the probiotic modulation of mucosal cellular immunity. Food Res. Int. 2014, 64, 283-288. [CrossRef]

167. Salehi, B.; Rescigno, A.; Dettori, T.; Calina, D.; Docea, A.O.; Singh, L.; Cebeci, F.; Özçelik, B.; Bhia, M.; Dowlati Beirami, A. Avocado-soybean unsaponifiables: A panoply of potentialities to be exploited. Biomolecules 2020, 10, 130. [CrossRef]

168. Fenster, K.; Freeburg, B.; Hollard, C.; Wong, C.; Rønhave Laursen, R.; Ouwehand, A.C. The Production and Delivery of probiotics: A review of a practical approach. Microorganisms 2019, 7, 83. [CrossRef] [PubMed]

169. Ranadheera, R.; Baines, S.; Adams, M. Importance of food in probiotic efficacy. Food Res. Int. 2010, 43, 1-7. [CrossRef]

170. Hempel, S.; Newberry, S.; Ruelaz, A.; Wang, Z.; Miles, J.N.; Suttorp, M.J.; Johnsen, B.; Shanman, R.; Slusser, W.; $\mathrm{Fu}, \mathrm{N}$. Safety of probiotics used to reduce risk and prevent or treat disease. Evid. Rep. Technol. Assess. 2011, 200, 1-645.

171. Marteau, P. Safety aspects of probiotic products. Näringsforskning 2001, 45, 22-24. [CrossRef] 
172. Govender, M.; Choonara, Y.E.; Kumar, P.; du Toit, L.C.; van Vuuren, S.; Pillay, V. A review of the advancements in probiotic delivery: Conventional vs. non-conventional formulations for intestinal flora supplementation. AAPS PharmSciTech 2014, 15, 29-43. [CrossRef] [PubMed]

173. Celiberto, L.S.; Pinto, R.A.; Rossi, E.A.; Vallance, B.A.; Cavallini, D.C.U. Isolation and Characterization of potentially probiotic bacterial strains from mice: Proof of concept for personalized probiotics. Nutrients 2018, 10, 1684. [CrossRef] [PubMed]

174. Salehi, B.; Calina, D.; Docea, A.O.; Koirala, N.; Aryal, S.; Lombardo, D.; Pasqua, L.; Taheri, Y.; Marina Salgado Castillo, C.; Martorell, M. Curcumin's nanomedicine formulations for therapeutic application in neurological diseases. J. Clin. Med. 2020, 9, 430. [CrossRef]

175. Cardona, F.; Andrés-Lacueva, C.; Tulipani, S.; Tinahones, F.J.; Queipo-Ortuño, M.I. Benefits of polyphenols on gut microbiota and implications in human health. J. Nutr. Biochem. 2013, 24, 1415-1422. [CrossRef]

176. Sireswar, S.; Dey, G.; Sreesoundarya, T.; Sarkar, D. Design of probiotic-fortified food matrices influence their antipathogenic potential. Food Biosci. 2017, 20, 28-35. [CrossRef]

177. Dueñas, M.; Muñoz-González, I.; Cueva, C.; Jiménez-Girón, A.; Sánchez-Patán, F.; Santos-Buelga, C.; Moreno-Arribas, M.; Bartolomé, B. A survey of modulation of gut microbiota by dietary polyphenols. BioMed Res. Int. 2015, 2015, 850902. [CrossRef]

178. Conti-Silva, A.C.; de Souza-Borges, P.K. Sensory characteristics, brand and probiotic claim on the overall liking of commercial probiotic fermented milks: Which one is more relevant? Food Res. Int. 2019, 116, 184-189. [CrossRef] [PubMed]

(C) 2020 by the authors. Licensee MDPI, Basel, Switzerland. This article is an open access article distributed under the terms and conditions of the Creative Commons Attribution (CC BY) license (http://creativecommons.org/licenses/by/4.0/). 